\title{
Water-filtered infrared A reduces chlamydial infectivity in vitro without causing ex vivo eye damage in pig and mouse models
}

Rahn, Carolin ; Marti, Hanna ; Blenn, Christian ; Leonard, Cory Ann ; Borel, Nicole ; Frohns, Antonia ; Frohns, Florian ; Barisani-Asenbauer, Talin

\begin{abstract}
Repeated ocular infections with Chlamydia trachomatis trigger the development of trachoma, the most common cause of infectious blindness worldwide. Water-filtered infrared A (wIRA) has shown positive effects on cultured cells and human skin. Our aim was to evaluate the potential of wIRA as a possible non-chemical treatment for trachoma patients. We both modeled ocular chlamydial infections using $\mathrm{C}$. trachomatis B to infect human conjunctival epithelial cells $(\mathrm{HCjE})$ and studied the effects of wIRA on non-infected ocular structures with two ex vivo eye models. We focused on the temperature development during wIRA irradiation in cell culture and perfused pig eyes to exclude potentially harmful side effects. Furthermore, cell viability of HCjE and cytotoxicity in mouse retina explants was analyzed. We demonstrated a significant wIRA-dependent reduction of chlamydial infectivity in HCjE cells. Moreover, we observed that wIRA treatment of HCjE prior to infection was sufficient to inhibit chlamydial infectivity and that visible light enhances the effect of wIRA. Irradiation did not reduce cell viability and there was no indication of retinal damage post treatment. Additionally, temperatures during wIRA exposure did not markedly exceed physiological eye temperatures, suggesting that hyperthermia-related lesions are unlikely. For clinical applications, further exploration of wIRA as a non-chemical treatment device in an experimental animal model is essential.
\end{abstract}

DOI: https://doi.org/10.1016/j.jphotobiol.2016.11.001

Posted at the Zurich Open Repository and Archive, University of Zurich

ZORA URL: https://doi.org/10.5167/uzh-127463

Journal Article

Accepted Version

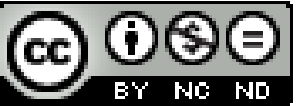

The following work is licensed under a Creative Commons: Attribution-NonCommercial-NoDerivatives 4.0 International (CC BY-NC-ND 4.0) License.

Originally published at:

Rahn, Carolin; Marti, Hanna; Blenn, Christian; Leonard, Cory Ann; Borel, Nicole; Frohns, Antonia; Frohns, Florian; Barisani-Asenbauer, Talin (2016). Water-filtered infrared A reduces chlamydial infectivity in vitro without causing ex vivo eye damage in pig and mouse models. Journal of Photochemistry and Photobiology B: Biology, (165):340-350.

DOI: https://doi.org/10.1016/j.jphotobiol.2016.11.001 


\section{Water-filtered infrared A reduces chlamydial infectivity in vitro}

2 without causing ex vivo eye damage in pig and mouse models

3

4 Carolin Rahn ${ }^{1}$, Hanna Marti ${ }^{1}$, Antonia Frohns ${ }^{2}$, Florian Frohns ${ }^{2}$, Christian Blenn ${ }^{1}$, Cory Ann

5

6

8

9

Leonard $^{1}$, Talin Barisani-Asenbauer ${ }^{3}$, Elisabeth Stein ${ }^{3}$, Nicole Borel ${ }^{1} \#$

${ }^{1}$ Institute of Veterinary Pathology, University of Zurich, Vetsuisse Faculty, Winterthurerstrasse 268, 8057 Zurich, Switzerland

${ }^{2}$ Technical University of Darmstadt, Schnittspahnstraße 10, 64287 Darmstadt, Germany

${ }^{3}$ Medical University of Vienna, Sensengasse 2a, 1090 Vienna, Austria

Email addresses: carolin.rahn@uzh.ch, hanna.marti@uzh.ch, antonia.frohns@gmail.com, frohns@bio.tu-darmstadt.de,christian.blenn@mgb.ch, coryann.leonard@uzh.ch, talin.barisani@meduniwien.ac.at, elisabeth.stein@meduni.ac.at, n.borel@access.uzh.ch

\section{\#Corresponding Author:}

Nicole Borel, DVM, FVH, Dipl. ECVP

Institute of Veterinary Pathology, Vetsuisse Faculty

University of Zurich, Winterthurerstrasse 268

$\mathrm{CH}-8057$ Zurich, Switzerland

Tel.: +41-44-635-8563

Fax.: +41-44-635-8934

Email: n.borel@access.uzh.ch 


\section{Abstract}

Repeated ocular infections with Chlamydia trachomatis trigger the development of trachoma, the most common cause of infectious blindness worldwide. Water-filtered infrared A (wIRA) has shown positive effects on cultured cells and human skin. Our aim was to evaluate the potential of wIRA as a possible non-chemical treatment for trachoma patients. We both modeled ocular chlamydial infections using $C$. trachomatis B to infect human conjunctival epithelial cells (HCjE) and studied the effects of wIRA on non-infected ocular structures with two ex vivo eye models. We focused on the temperature development during wIRA irradiation in cell culture and perfused pig eyes to exclude potentially harmful side effects. Furthermore, cell viability of $\mathrm{HCjE}$ and cytotoxicity in mouse retina explants were analyzed.

We demonstrated a significant wIRA-dependent reduction of chlamydial infectivity in HCjE cells. Moreover, we observed that wIRA treatment of $\mathrm{HCjE}$ prior to infection was sufficient to inhibit chlamydial infectivity and that visible light enhances the effect of wIRA. Irradiation did not reduce cell viability and there was no indication of retinal damage post treatment. Additionally, temperatures during wIRA exposure did not markedly exceed physiological eye temperatures, suggesting that hyperthermia-related lesions are unlikely. For clinical applications, further exploration of wIRA as a non-chemical treatment device in an experimental animal model is essential.

Keywords: Chlamydiaceae, vitreous body, retina, temperature, cytotoxicity 


\section{Introduction}

Trachoma is a human infectious ocular disease and a major cause of preventable blindness worldwide, specifically in Africa, Asia, Central and South America, Australia and the Middle East. Approximately 229 million people are currently at risk of contracting trachoma according to the World Health Organization (WHO). Conjunctival infection with Chlamydia (C.) trachomatis ocular strains A, B or $\mathrm{C}$ marks the onset of trachoma and is followed by four clinical stages: i) papillary hypertrophy and lymphoid follicles (active trachoma), affecting an estimated 21 million people, ii) accumulation of scar tissue in the conjunctiva, iii) eyelid distortion and scarring of the cornea through rubbing lashes (trichiasis, affecting approximately 7.3 million people) and iv) corneal opacification leading to irreversible blindness, with approximately 1.2 million people affected worldwide (1-3).

To date, the SAFE strategy is used in an attempt to eliminate endemic blinding trachoma, and includes Surgery for trachomatous trichiasis, Antibiotic treatment, Facial cleanliness and Environmental improvement such as general community hygiene, adequate water supply and construction of sanitary facilities (2-4). For individuals suffering from active trachoma, antibiotic treatment with azithromycin or doxycycline is the most common therapy and is often applied via mass drug administration (MDA) in endemic regions as part of the elimination program (4). A study by West et al. demonstrated that even after multiple MDA treatments, one third of the patients still had eye infections with C. trachomatis. Although they did not find evidence for azithromycin resistance, the possibility could not be ruled out completely (5). Antimicrobial resistance in general has become a major public health concern in recent years. Pathogens have developed resistance to multiple classes of antibiotics, so the limitation of antibiotic use is encouraged worldwide, especially in food production herds (6).

Of particular interest is the emergence of tetracycline resistance in C. suis, a growing problem in the pig rearing industry and probably the result of excessive tetracycline use for therapeutic purposes and as growth promoters in livestock since the 1950s (7-11). C. suis is primarily known to inapparently infect the porcine gastrointestinal tract with a prevalence of up to $90 \%$ in fattening pigs (12). Together with $C$. trachomatis, C. suis belongs to the obligate intracellular and Gram-negative bacterial family Chlamydiaceae, which is characterized by a unique biphasic lifecycle consisting of infectious elementary bodies (EBs) and intracellular, dividing reticulate bodies (RBs) $(12,13)$. Alarmingly, mixed infections with $C$. trachomatis and $C$. suis have been reported in Nepalese trachoma patients, while co-infection of the two closely related species generated tetracycline resistant $C$. trachomatis strains in 
vitro $(14,15)$. Taking these findings together, mixed infection with tetracycline resistant $C$. suis and ocular C. trachomatis strains may amplify the emergence of therapy-resistant trachoma strains. Therefore, the development of alternative, preferably non-chemical, treatment methods may aid achievement of the WHO goal established in 1997 to eliminate trachoma by the year 2020 (3).

Water-filtered infrared A radiation (wIRA) with a radiation spectrum ranging from 780 to $1400 \mathrm{~nm}$ has been used successfully, either alone or in combination with visible light (VIS), to aid the healing process of acute and chronic wounds, improving tissue oxygen partial pressure and perfusion, as well as reducing pain, inflammation and the frequency of wound infection (16-19) .

In our previous studies, we demonstrated that wIRA or wIRA/VIS treatment reduced chlamydial infectivity in permanent cell lines such as HeLa and Vero cells $(20,21)$. Here, our goal was to study the effect of wIRA with and without visible light on an established in vitro ocular infection model to investigate the possibility of wIRA as a potential treatment for trachoma. We infected human conjunctival epithelial cells with the ocular serovar Chlamydia trachomatis B, irradiated cells and/or bacteria, either prior to infection or 40 hours post infection, and evaluated the potential reductive effect of wIRA or wIRA/VIS on chlamydial infectivity. Since the eye is a highly complex and heterogeneous organ with different anatomic structures such as the cornea, the vitreous body and the thermo- and photo-sensitive retina (22), we further investigated the effect of wIRA and wIRA/VIS irradiation on the non-infected eye. First, we focused on temperature inside the cornea, sclera and the vitreous body of isolated pigs eyes during irradiation. Pig eyes were chosen due to their similarity to human eyes in regards to size as well as histological and physiological features (23). Second, in order to investigate the effect of wIRA irradiation and temperature on the retina, we used adult and postnatal mouse retina explants, an established ex vivo organ model that is known to be particularly sensitive to stressors (24-26). Both eye models were evaluated for temperature changes upon irradiation. The retina explant model was further examined via ELISA, for activation of various markers of cytotoxicity. In summary, we demonstrated that the vitreal temperature, which can affect the neighboring thermosensitive retina, is increased up to $38.4{ }^{\circ} \mathrm{C}$ in pig eyes at irradiation doses used to treat infection in vitro. However, wIRA/VIS does not activate markers of cytotoxicity such as phosphorylated p38, Akt, Erk or SAPK/JNK in the highly photo- and heat-sensitive retinae of adult and postnatal mice. In addition, we show that both wIRA and wIRA/VIS reduce $C$. trachomatis in an in vitro eye infection model. In particular, the combined irradiation of cells and EBs prior infection has a strong inhibiting effect on chlamydial infectivity. Taken together, these data indicate that this study is an important early 
step in the potential introduction of wIRA or wIRA/VIS as a new, non-chemical treatment method to aid the elimination of trachoma.

\section{Material and Methods}

\subsection{Preparation of isolated pig eyes}

Pig eyes were obtained from an abattoir and transported on ice. Post mortem time of experiments ranged from one to eight hours. Perfusion of eyes was modified from the method described by Wilson et al. (27) and Shahidullah et al. (28), (Figure 1). Briefly, the ciliary artery was cannulated with a $25 \mathrm{G}$ needle at the point where it enters the sclera. The eyes were placed in a water bath (with temperature adjusted for each experiment), containing Krebs' solution [mM: $\mathrm{NaCl}, 118 ; \mathrm{KCl}, 4.7 ; \mathrm{MgSO}_{4}, 1.2$; $\mathrm{CaCl}_{2}, 2.5 ; \mathrm{NaHCO}_{3}, 25 ; \mathrm{KH}_{2} \mathrm{PO}_{4}, 1.2$; glucose, 11.5; ascorbate 0.05; glutathione, $\left.1.0(\mathrm{pH} 7.4)\right]$. The cornea was not covered by the solution. The perfusion with Krebs' solution was performed with a peristaltic pump (Watson marlow 505U) with a flow rate of $1.4 \mathrm{~mL} / \mathrm{min}$. To mimic physiologic conditions during irradiation, the cornea was washed constantly with Krebs' solution by the same peristaltic pump. A digital pressure transducer (Greisinger GMH5155) was used to measure the arterial pressure to ensure it did not exceed $140 \mathrm{mmHg}$. Perfusion was checked before and after each experiment. Successful perfusion was indicated by constant flow through the vortex veins. For temperature measurement, sensors of a digital thermometer (Testo735, Testo AG, Lenzkirch, Germany) were placed in the middle of the vitreous body and on the top of the cornea. 


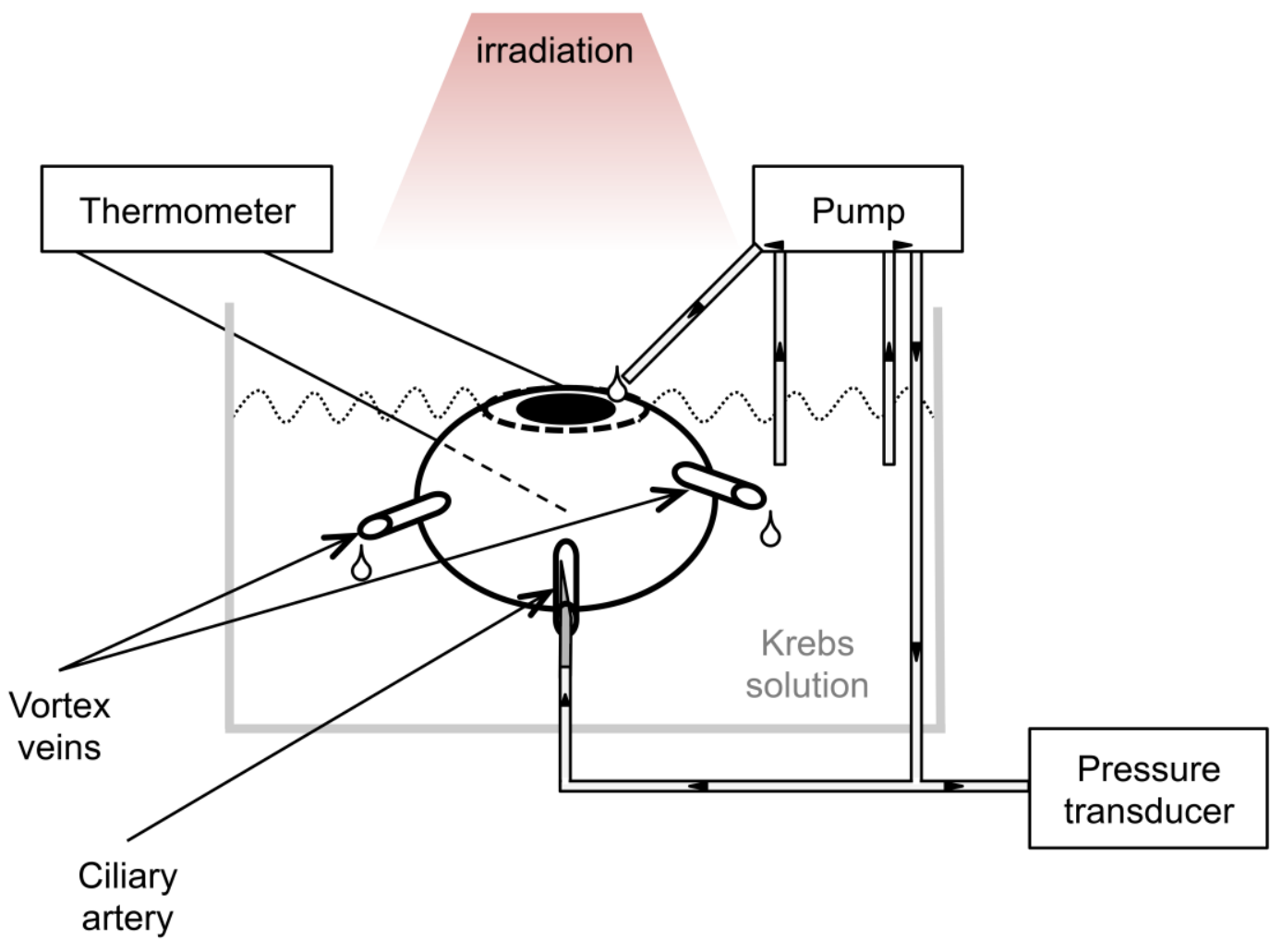

Figure 1. Schematic diagram of the pig eye perfusion model

Pig eyes were placed in a water bath with Krebs' solution, with the cornea not covered by the solution. Perfusion was performed by cannulating the ciliary artery, pumping the solution through the eyes by a peristaltic pump with a constant flow rate, representing arterial pressure, and draining through the vortex veins. The cornea was constantly washed with Krebs' solution by the same peristaltic pump. The temperature during irradiation was measured in the middle of the vitreous body or on the top of the cornea.

\subsection{Irradiation of isolated pig eyes}

Pig eyes were exposed to wIRA/VIS with a final radiation spectrum ranging from 595 to $1400 \mathrm{~nm}$ for 30 min using a Hydrosun 750 wIRA radiator (Hydrosun $\mathrm{GmbH}$, Müllheim, Germany) with an orange filter (BTE 595, Hydrosun $\mathrm{GmbH}$ ) at irradiation doses of 1000, 2100, 3700 and $5000 \mathrm{~W} / \mathrm{m}^{2}$. In another set of experiments, pig eyes were irradiated with wIRA alone for 30 min using a black filter (RG 780, Hydrosun $\mathrm{GmbH}$ ) emitting a spectrum of 780 to $1400 \mathrm{~nm}$, at $2000 \mathrm{~W} / \mathrm{m}^{2}$, which is the corresponding irradiation dose of wIRA/VIS $2100 \mathrm{~W} / \mathrm{m}^{2}$ if the BTE 595 is used. 


\subsection{Preparation, temperature exposure and irradiation of mouse retina explants}

All experiments were conducted according to the directive 2010/63/EU of the European Parliament. Mice were housed under conventional conditions with food and water available ad libitum and a 12-h light cycle. The eyes of adult or postnatal (10 days old, P10) C57BL/6 mice were removed after killing by cervical decapitation; the retinae with the vitreous bodies were isolated by using a binocular microscope and cultured with $500 \mu$ medium per well [DMEM complemented with $10 \%$ FCS, $1 \%$ Lglutamine, $1 \%$ nonessential amino acids, $100 \mathrm{U} / \mathrm{mL}$ penicillin, and $0.1 \mathrm{mg} / \mathrm{mL}$ streptomycin] in a 24well plate (TPP, Trasadingen, Switzerland) at $37{ }^{\circ} \mathrm{C}$ and $5 \% \mathrm{CO}_{2}$ for $30 \mathrm{~min}$ as previously described (29). Subsequently, well plates were placed into a circulating water bath at $37^{\circ} \mathrm{C}$ or $40^{\circ} \mathrm{C}$ inside of an incubator $\left(37^{\circ} \mathrm{C}\right)$ for another 30 min with (+wIRA) and without (Ctrl) wIRA/VIS treatment (BTE 595) at $1000 \mathrm{~W} / \mathrm{m}^{2}$. For ELISA analysis, vitreous bodies were removed from the retinae before fixation by snap freezing. Retinae were placed in cell lysis buffer and sonicated three times for 1 min each (Cell Signaling Technologies, Cambridge, UK, \#9803). ELISA assay for p-p38 (Cell Signaling Technology, \#7946), pAkt (Cell Signaling Technology, \#7252), pErk (Cell Signaling Technology, \#7177) and pSAPK/JNK (Cell Signaling Technology, \#7325) was performed according to the manufacturer's protocol.

\subsection{Host cells and media}

For cell culture experiments, human conjunctival epithelial cells ( $\mathrm{HCjE})$, immortalized by hTERT transfection, which were kindly donated by Prof. llene Gipson (Schepens Eye Research Institute, Harvard Medical School, Boston) (30), were used for the infection experiments. Reinfection experiments were performed in HeLa cells (Homo sapiens cervix adenocarcinoma, CCL-2 ATCC). For cell propagation, the cell lines were incubated at $37^{\circ} \mathrm{C}$ and $5 \% \mathrm{CO}_{2}$ in growth culture medium. $\mathrm{HCjE}$ growth medium consisted of Keratinocyte Serum-Free Medium (GIBCO, Invitrogen, Carlsbad, CA, USA) supplemented with $25 \mu \mathrm{g} / \mathrm{mL}$ bovine pituitary extract (BPE, GIBCO), $0.2 \mathrm{ng} / \mathrm{mL}$ epidermal growth factor (EGF), $0.4 \mathrm{mM}$ calcium chloride (Sigma-Aldrich Co., St. Louis, MO, USA) and $0.2 \mathrm{mg} / \mathrm{L}$ gentamycin (50 mg/mL, GIBCO). Neutralization medium, composed of Dulbecco`s Modified Eagle Medium/Nutrient Mixture F-12 (DMEM/F12, GIBCO) with $10 \%$ fetal calf serum (FCS, BioConcept, Allschwil, Switzerland) was used for the thawing of cells, serial passaging and infection of $\mathrm{HCjE}$, as previously described (30). 
HeLa growth medium consisted of Minimal Essential Medium (MEM) with Earle's salts, 25 mM HEPES, without L-Glutamine (GIBCO) supplemented with $10 \%$ fetal calf serum (BioConcept), $4 \mathrm{mM}$ GlutaMAX-I (200mM, GIBCO), $0.2 \mathrm{mg} / \mathrm{mL}$ gentamycin (50 mg/mL, GIBCO) and 1\% MEM NonEssential Amino Acids (MEM NEAA, 100x, GIBCO).

For infection experiments, cells were seeded on glass coverslips (13 $\mathrm{mm}$ diameter, Sterilin Limited; Thermo Fisher Scientific, Waltham, MA, USA), which were placed in 24-well plates (Techno Plastic Products AG (TPP), Trasadingen, Switzerland). Prior to seeding HCjE, coverslips were coated with 50 $\mu \mathrm{g} / \mathrm{mL}$ Rat-Tail Collagen I (Discovery Labware, Inc., Bedford, MA, USA) diluted in $0.02 \mathrm{~N}$ acetic acid (Carl Roth, Karlsruhe, Germany). When cells reached a confluency of $80-90 \%$, they were plated at a density of $1.5 \times 10^{5}$ cells/well and grown for 48 hours in $1 \mathrm{~mL}$ growth medium. HeLa cells were processed as previously described (20).

\subsection{Chlamydial strains}

In the present study, Chlamydia (C.) trachomatis, serotype B (strain HAR-36, VR-573 ATCC, kindly provided by T. Barisani-Asenbauer, Vienna, Austria) was used for all infection experiments with $\mathrm{HCjE}$ cells. The strain was propagated and stored at $-80{ }^{\circ} \mathrm{C}$ as previously described (20), in LLC-MK2 cells (CCL-7 ACCT, kindly provided by M. Donati, Bologna, Italy) as reported previously (31) .

\subsection{Irradiation of $\mathrm{HCjE}$ and temperature measurement during irradiation}

In this study, infected and non-infected cells were exposed either to wIRA alone (RG 780) or wIRA/VIS (BTE 595) for $30 \mathrm{~min}$ at $2000 \mathrm{~W} / \mathrm{m}^{2}$ and $2100 \mathrm{~W} / \mathrm{m}^{2}$, respectively.

Aiming for a stable temperature during irradiation, 24-well plates were placed into a circulating waterbath (SC100, Thermo Fisher Scientific), which served as a cooling system with an adjusted temperature of $37^{\circ} \mathrm{C}$. Intra-well temperature was checked every 5 min during 30 min of irradiation with a Voltcraft thermometer (Type 2ABAc, Philips, Kassel, Germany) as previously described (20).

\subsection{Determination of cell viability}

\subsubsection{AlamarBlue assay}

$10 \%$ AlamarBlue dye (Biozol, Eching, Germany) was added to the wells immediately after irradiating non-infected HCjE once or four times $(0 \mathrm{~h}, 2 \mathrm{~h}, 5 \mathrm{~h}$ and $8 \mathrm{~h})$ for $30 \mathrm{~min}$ with $2000 \mathrm{~W} / \mathrm{m}^{2}$ wIRA or 2100 $\mathrm{W} / \mathrm{m}^{2}$ wIRA/VIS. Plates were then incubated for $3 \mathrm{~h}$ at $37^{\circ} \mathrm{C}$ and fluorescence was determined at 560 
$204 \mathrm{~nm}$ excitation and $590 \mathrm{~nm}$ emission wavelength (LS55 luminescence spectrometer, Perkin-Elmer) as 205 previously described (32). Heat denatured cells (h.d.) served as a positive control. 


\subsubsection{Evaluating average number of cells per field}

207

208

209

210

211

212

213

214

215

216

217

218

219

220

221

222

223

224

225

226

227

228

229

230

231

232

233

234

235

236

After fixation of cell cultures in $1 \mathrm{~mL}$ methanol for $10 \mathrm{~min}$, nuclei were stained with 4',6-Diamidin-2'phenylindoldihydrochlorid (1:1000, DAPI, $1 \mu \mathrm{g} / \mathrm{mL}$, Molecular Probes, Eugene, OR, USA) and coverslips were mounted on glass slides using FluoreGuard Mounting (Hard Set, ScyTek Laboratories Inc., Logan, UT, USA) before examination using a DMLB fluorescence microscope (Leica Microsystems, Wetzlar, Germany). Briefly, the number of nuclei per high-power field was counted in ten microscopic fields at 1000 -fold magnification on oil immersion with a 100x objective (PL FLUOTAR 100x/1.30, OIL, $\infty / 0.17 / D$, Leica Microsystems) and a 10x ocular objective (Leica L-Plan 10x/25M, Leica Microsystem), followed by determination of the mean value. The mean number of nuclei per field of irradiated samples was then compared to control (non-irradiated) samples.

\subsection{Experimental design of infection}

\subsubsection{Irradiation of infected HCjE at 40 hours post infection (hpi)}

HCjE were seeded on a 24-well plate, incubated for $48 \mathrm{~h}$ and infected with EBs at a multiplicity of infection (MOI) of 0.1 or 1 . Briefly, EBs were diluted in $1 \mathrm{~mL}$ neutralization medium per sample and used to inoculate $100 \%$ confluent $\mathrm{HCjE}$ monolayers. Plates were then centrifuged for 1 hour at $1000 \mathrm{~g}$ and $25{ }^{\circ} \mathrm{C}$. Afterwards, inocula were aspirated and replaced by $1 \mathrm{~mL}$ incubation medium without gentamycin for further incubation of plates at $37^{\circ} \mathrm{C}$ and $5 \% \mathrm{CO}_{2}$. At $40 \mathrm{hpi}$, infected monolayers were irradiated with wIRA alone or wIRA/VIS, as described in 2.6, and incubated for $3 \mathrm{~h}$ before they were fixed in methanol for immunofluorescence or collected for titration by sub-passage as previously described (20) (Figure 2A). Non-irradiated cultures were used as controls.

\subsubsection{Irradiation of EBs and HCjE prior to infection}

For this experiment, $\mathrm{HCjE}$ were seeded and incubated for $48 \mathrm{~h}$. During incubation, cell monolayers were irradiated four times $8 \mathrm{~h}, 6 \mathrm{~h}, 3 \mathrm{~h}$ and immediately before infection with EBs, which had been exposed to irradiation by transferring $1 \mathrm{~mL}$ of EB-containing medium to a cell-free 24-well plate for treatment as previously established $(20,21)$. Irradiation was performed with either wIRA alone or wIRA/VIS for $30 \mathrm{~min}$ as shown in 2.6.

In total, there were four conditions: i) non-irradiated cells with non-irradiated EBs (control, E-C-), ii) irradiated cells with non-irradiated EBs (E-C+), iii) non-irradiated cells with irradiated EBs $(E+C-)$ and iv) irradiated cells with irradiated $E B s(E+C+)$. After infection with $E B s$, plates were incubated for $43 \mathrm{~h}$ 

collected for reinfection as described in 2.9. (Figure 2B).

\section{A) Irradiation 40 hours post infection}

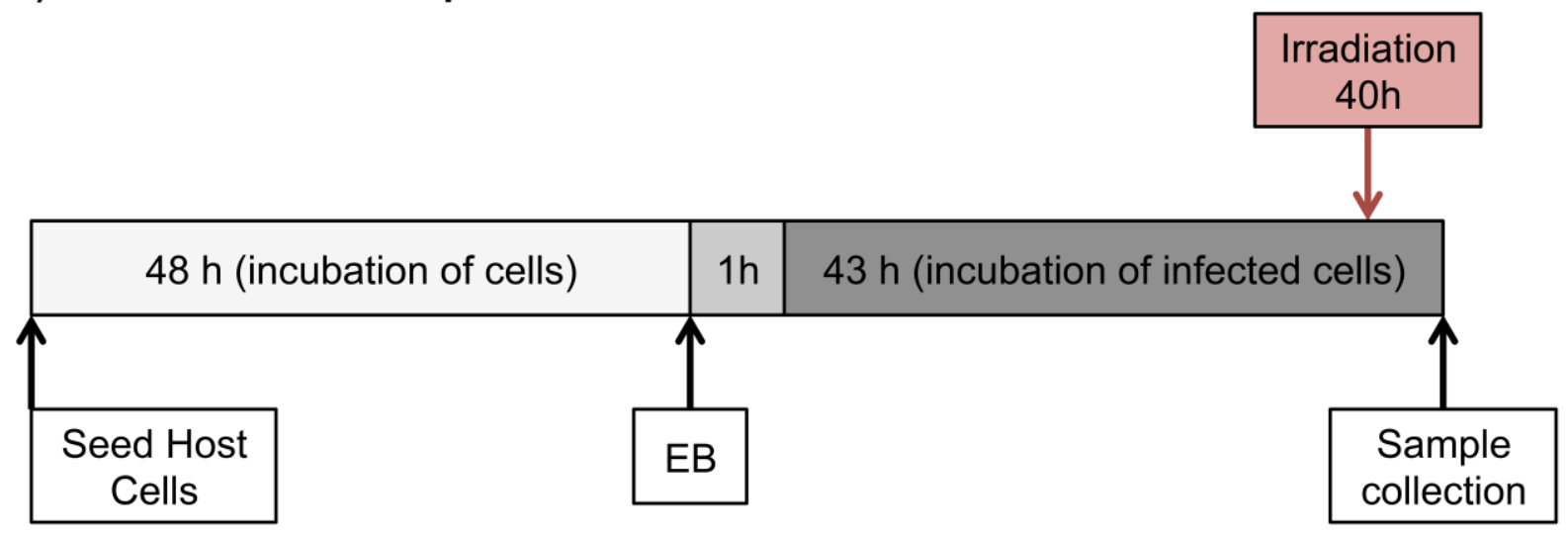

\section{B) Irradiation of EBs and cells prior infection}

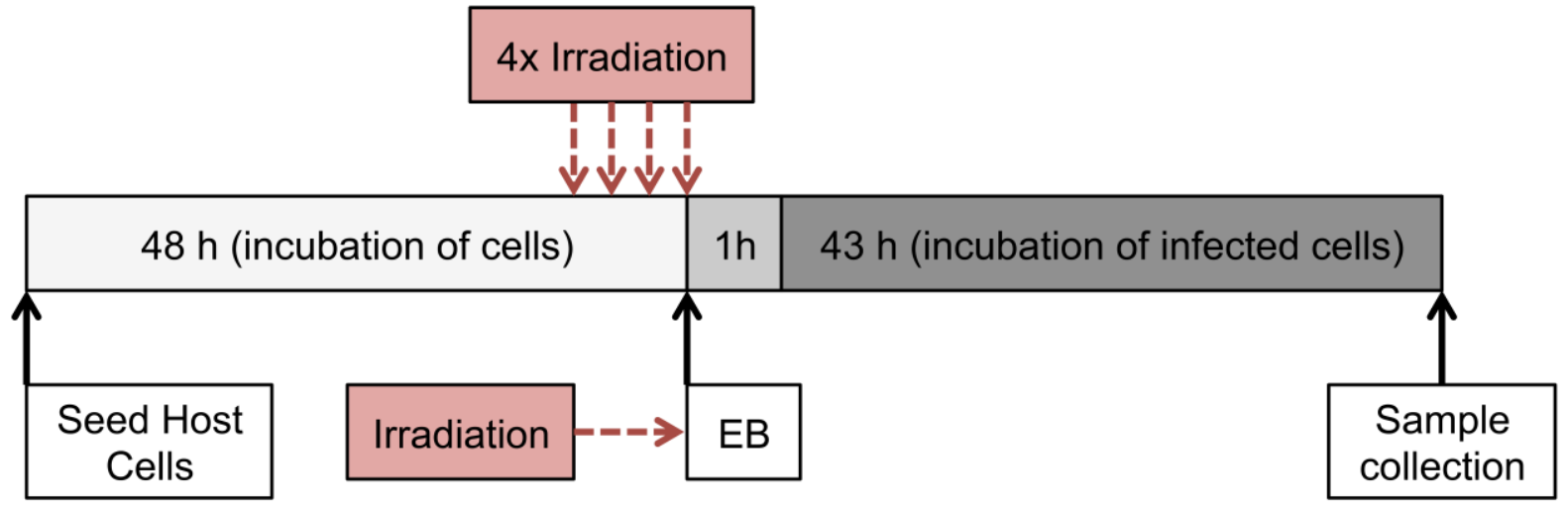

Figure 2. Study design of the eye infection model. (2 columns)

Human conjunctival epithelial cells $(\mathrm{HCjE})$ were seeded and incubated for $48 \mathrm{~h}$ prior to infection with EBs (C. trachomatis serotype B) at a multiplicity of infection (MOI) 0.1 or 1 . After centrifugation at 1000 $\mathrm{g}$ for $1 \mathrm{~h}\left(25^{\circ} \mathrm{C}\right)$, infected cultures were incubated and samples were collected for titration by subpassage at $43 \mathrm{~h}$ post infection (hpi). Time of irradiation treatment (prior or post infection) depended on the experiment. Irradiation was performed either with wIRA alone (2000 W/m², RG 780 filter) or wIRA in combination with visible light $\left(2100 \mathrm{~W} / \mathrm{m}^{2}\right.$, BTE 595) for 30 min per treatment. (A) Infected cell cultures were irradiated at $40 \mathrm{hpi}$ (red arrow).

(B) Cells were irradiated four times $(8 \mathrm{~h}, 6 \mathrm{~h}, 3 \mathrm{~h}, 0 \mathrm{~h})$ before they were infected with EBs, which had been irradiated or not immediately prior to infection (red arrows with dashed lines). 


\subsection{Immunofluorescence staining and microscopy}

Prior to immunofluorescence staining, cultures were fixed in methanol at $40 \mathrm{hpi}$ or $43 \mathrm{hpi}$. Indirect immunofluorescence assays (IFA) were performed with a primary Chlamydiaceae family-specific mouse monoclonal antibody (1:200, LPS, Clone ACI-P, Progen, Heidelberg, Germany), detecting the chlamydial lipopolysaccharide and a secondary Alexa Fluor 488-goat anti-mouse antibody (1:500, Molecular Probes, Eugene, OR, USA), as previously described (20). DNA was stained with DAPI (1:1000, $1 \mu \mathrm{g} / \mathrm{mL})$. After immunolabeling, coverslips were fixed onto glass slides and examined with a DMLB fluorescence microscope as described in 2.7.2. Samples from the original infection were screened at 1000 -fold magnification on oil immersion, counting the number of nuclei and chlamydial inclusions in ten fields to determine the infection rate, whereas the number of inclusions per field was determined in 30 fields per coverslip for reinfection experiments at 200-fold magnification using a 20x objective (PL FLUOTAR 20x/0.50 PH2, $\infty / 0.17 / \mathrm{B}$ ) and a 10x ocular objective (Leica L-Plan 10x/25 M, Leica Microsystems) as previously described (21).

\subsection{Titration by sub-passage / Reinfection experiments}

Samples for titration by sub-passage were collected at 43 hpi by scraping the cell monolayer into the medium. The samples were then stored at $-80^{\circ} \mathrm{C}$. After thawing, infected cells were sonicated for 5 min with a sonicator (Brandson 250 Sonifier, Danbury, CT, USA) and used for titration by sub-passage in HeLa cells as previously described $(20,33)$.

Briefly, a serial dilution was performed on a 24-well plate seeded with HeLa cells before centrifugation for 1 hour at $1000 \mathrm{~g}$ and replacement of the inoculum with $1 \mathrm{~mL}$ of HeLa growth medium (without gentamycin) supplemented with $1 \mu \mathrm{g} / \mathrm{mL}$ cycloheximide (Sigma-Aldrich). At $40 \mathrm{hpi}$, cultures were fixed and immunolabeled as described in 2.9. For analysis, the number of inclusions at 200 -fold magnification in 30 random microscopic fields were counted and the number of inclusion-forming units (IFU) in undiluted inoculum was determined and expressed as IFU per $\mathrm{mL}$ as previously described (32).

\subsection{Statistical analysis}

All statistical analyses were performed with the GraphPad Quickcalcs software (www.graphpad.com/quickcalcs) as previously described (21). If not stated otherwise, all results are presented as means \pm standard deviation (SD) of the indicated number of experiments. The 
significance of differences was estimated by the unpaired $t$ test for all cell culture experiments and a pvalue of $<0.05$ was considered significant. One-way ANOVA followed by Tukey-test for multiple groups was used for comparison of temperature increase in the pig eyes experiments and experiments with mouse retina explants after varying doses of wIRA. Unpaired two-tailed student's t-test was used for ELISA analysis. For all analyses a $\mathrm{Cl}=95 \%$ with ${ }^{*} \mathrm{p}<0.05$, ${ }^{* *} \mathrm{p}<0.01$ and ${ }^{* * *} \mathrm{p}<0.001$ was defined as statistically significant.

\section{Results}

3.1 wIRA-induced temperature increase is not altered by the visible light component in intrawell or cornea but is slightly elevated in the vitreous body.

In a previous study, we showed that visible light $(380-780 \mathrm{~nm})$ significantly contributed to the increase of intra-well temperature at high doses of irradiation in in vitro cultured cells (21). Consequently, we investigated whether this significant rise in intra-well temperature also occurs at a visible light spectrum of 595 to $780 \mathrm{~nm}$, and how the temperature curve compares to those generated in ex vivo models. Briefly, we evaluated the temperature curve both within the wells of a 24 -well plate of cultured cells and in ex vivo in pig eyes during irradiation with wIRA alone or with wIRA/VIS for 30 min. For the in vitro infection model, $\mathrm{HCjE}$ cells were seeded on coverslips in 24-well plates and the intra-well temperature was measured at the bottom of the wells every $5 \mathrm{~min}$. For wIRA alone, the starting temperature was $35.41{ }^{\circ} \mathrm{C}\left( \pm 0.25^{\circ} \mathrm{C}\right)$ followed by a rapid increase to $37.23^{\circ} \mathrm{C}\left( \pm 0.2{ }^{\circ} \mathrm{C}\right)$ within $5 \mathrm{~min}$ before reaching a plateau of approximately $37.7^{\circ} \mathrm{C}$ after $10 \mathrm{~min}$ of irradiation. The temperature curve of wIRA/VIS looked similar to that of wIRA alone, though the starting temperature was slightly lower with $34.39{ }^{\circ} \mathrm{C}\left( \pm 0.73{ }^{\circ} \mathrm{C}\right.$, Figure $3 \mathrm{~A}$, left panel). After $30 \mathrm{~min}$ of irradiation, the final intra-well temperature was $37.71^{\circ} \mathrm{C}\left( \pm 0.12^{\circ} \mathrm{C}\right)$, which was not significantly different from wIRA/VIS irradiation $\left(37.54 \pm 0.07^{\circ} \mathrm{C}\right.$, Figure $3 \mathrm{~A}$, right panel).

The vitreal temperature of perfused pig eyes was adjusted to the physiological temperature of $34{ }^{\circ} \mathrm{C}$ (34). WIRA/VIS was then applied for 30 min, which led to a rapid increase in temperature within the first 10 min of treatment before reaching a plateau similar to that of irradiated $\mathrm{HCjE}$ in a 24-well plate (Figure 3B, left panel). Interestingly, we found that the final vitreal temperature was significantly lower following wIRA/VIS irradiation $\left(37.64{ }^{\circ} \mathrm{C} \pm 0.34{ }^{\circ} \mathrm{C}\right)$ compared to wIRA alone $\left(38.4 \pm 0.73{ }^{\circ} \mathrm{C}\right.$, Figure $3 \mathrm{~B}$, right panel). In contrast to irradiation of $\mathrm{HCjE}$ and the vitreous body, where the mean temperature increased up to $38{ }^{\circ} \mathrm{C}$ in the course of $30 \mathrm{~min}$ and a plateau was reached within the first $5-10 \mathrm{~min}$, 
average surface temperature of the cornea did not exceed $35^{\circ} \mathrm{C}$. Initial corneal temperature started at after 30 min for wIRA alone and wIRA/VIS, respectively (Figure 3C, left panel). Similar to irradiation of

$317 \mathrm{HCjE}$, the temperature differences between the two irradiation spectra groups were not significant

318 (Figure 3C, right panel).
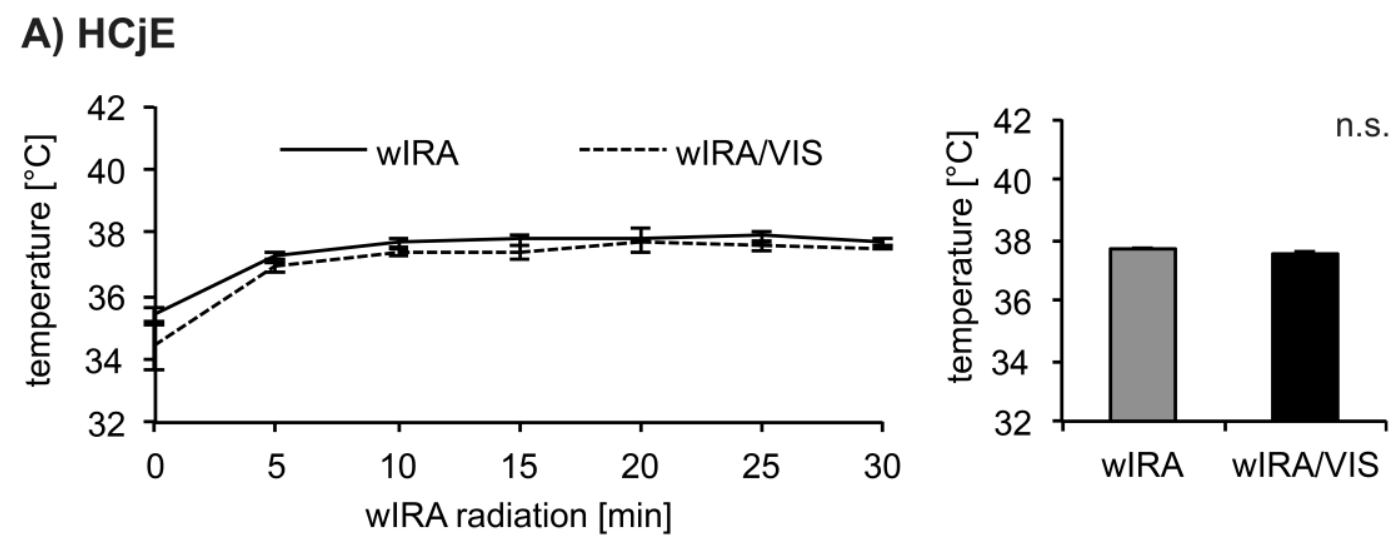

\section{B) Vitreous Body}
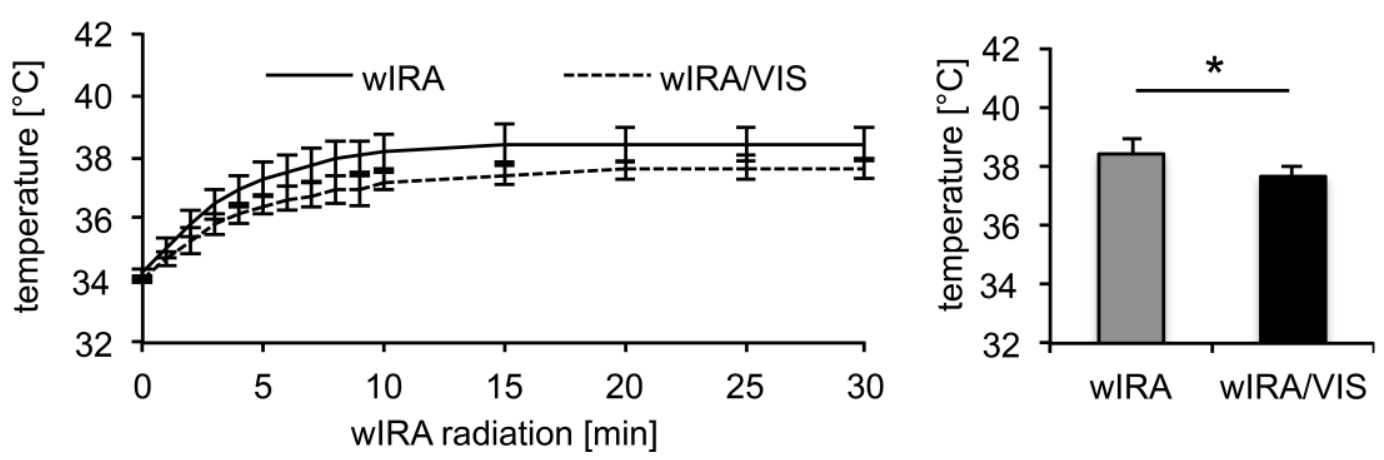

\section{C) Cornea}
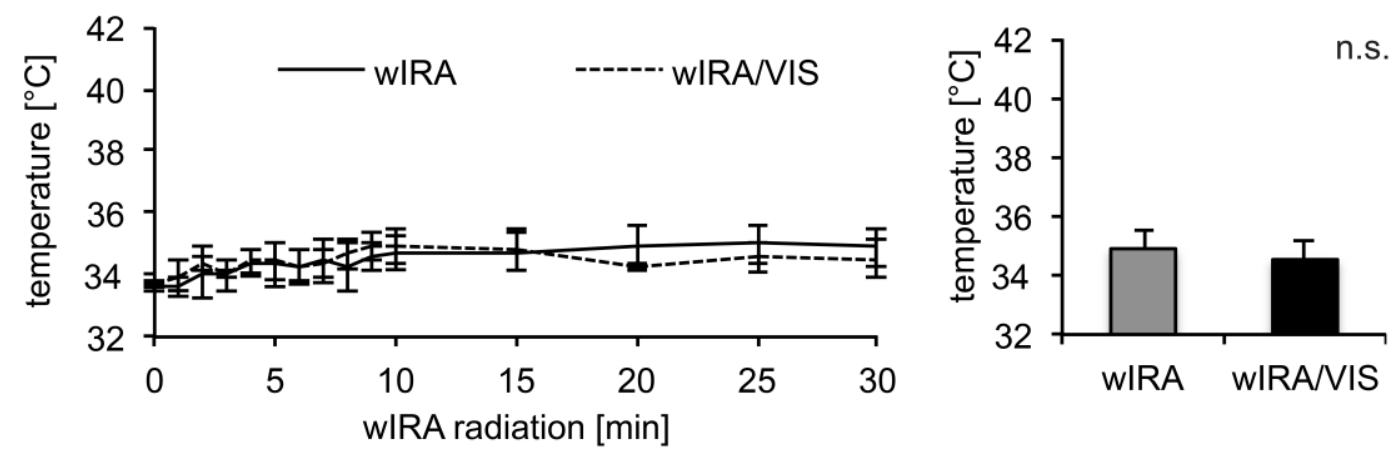

Figure 3. The visible light component $(595-780 \mathrm{~nm})$ does not significantly increase intra-well, 
(A) Monolayers of $\mathrm{HCjE}$ seeded on a 24-well plate were irradiated for 30 min with either wIRA alone (RG 780 filter, $2000 \mathrm{~W} / \mathrm{m}^{2}$ ) or wIRA and visible light (BTE 595, $2100 \mathrm{~W} / \mathrm{m}^{2}$ ). The mean intra-well temperature of three wells per condition was evaluated every $5 \mathrm{~min}$ in three independent experiments. Shown is the temperature profile for each condition in the course of irradiation (left panel) and the mean intra-well temperature after 30 min of irradiation (right panel; mean $\pm \mathrm{SD}$; $\mathrm{n}$.s. not significant; $\mathrm{t}$ test). Additionally, perfused pig eyes were irradiated similarly after adjusting (B) the vitreal or (C) the corneal temperature to $34{ }^{\circ} \mathrm{C}$ whereupon the temperature was measured constantly (mean $\pm \mathrm{SD} ; \mathrm{n}=3$ for wIRA alone; $n=5$ for wIRA/VIS, * $p<0.05$; one way ANOVA).

\subsection{WIRA/VIS increases vitreal and corneal temperature of constantly perfused pig eyes in a} dose dependent manner.

As determined in our previous experiment, wIRA/VIS and wIRA treatments result in similar temperature curves, despite varying vitreal temperature, after $30 \mathrm{~min}$. Therefore, in order to further investigate the influence of the irradiation dose in an ex vivo model, we irradiated perfused pig eyes with wIRA/VIS for $30 \mathrm{~min}$ at 1000, 2100, 3700 and $5000 \mathrm{~W} / \mathrm{m}^{2}$. As expected, we found a positive correlation between temperature increase and irradiation dose, with each dose significantly varying from the other. For example, the vitreal temperature was significantly increased during irradiation at $1000 \mathrm{~W} / \mathrm{m}^{2}(p=0.0025)$ and the final vitreal temperature was $35.8^{\circ} \mathrm{C} \pm 0.4^{\circ} \mathrm{C}$ after $30 \mathrm{~min}$, in contrast to a final temperature of $41.3^{\circ} \mathrm{C}\left( \pm 0.7^{\circ} \mathrm{C}\right)$ following treatment at $5000 \mathrm{~W} / \mathrm{m}^{2}$ (Figure $4 \mathrm{~A}$ ).

In opposition to the vitreous body results, continuous temperature measurement of the constantly perfused corneal surface resulted in a different irradiation dose response. Neither $1000 \mathrm{~W} / \mathrm{m}^{2}$ nor $2100 \mathrm{~W} / \mathrm{m}^{2}$ of wIRA/VIS induced a significant increase against the physiological start temperature of $34{ }^{\circ} \mathrm{C}$ (34-36) (Figure 4B). However, higher doses led to a significant temperature increase after 30 min at $3700 \mathrm{~W} / \mathrm{m}^{2}$ and $5000 \mathrm{~W} / \mathrm{m}^{2}$ with $38.6{ }^{\circ} \mathrm{C} \pm 1.13^{\circ} \mathrm{C}$ and $41.13^{\circ} \mathrm{C} \pm 0.93^{\circ} \mathrm{C}$ observed, respectively. 


\section{A) Vitreous Body}

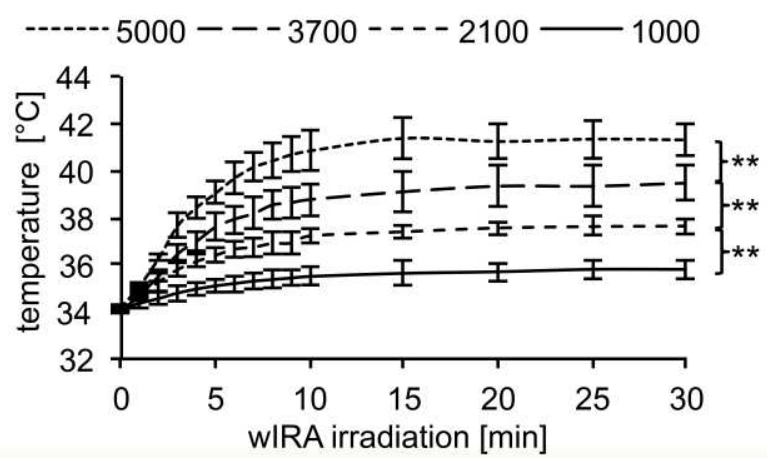

\section{B) Cornea}

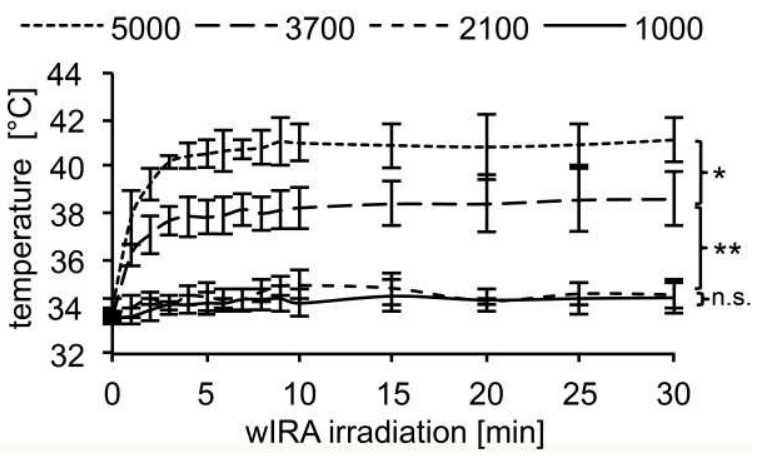

349

350

351

352

353

354

355

356

357

358

359

360

361

362

363

364

365

366

367

368

369

370

371

372

Figure 4. wIRA/VIS increases vitreal and corneal temperature of constantly perfused pig eyes in a dose dependent manner. ( 2 columns)

Perfused pig eyes were irradiated with wIRA and visible light (BTE 595) at varying irradiation doses $\left(1000,2100,3700\right.$ and $\left.5000 \mathrm{~W} / \mathrm{m}^{2}\right)$ for $30 \mathrm{~min}$ after initial adjustment of the vitreal or corneal temperature to $34{ }^{\circ} \mathrm{C}$. The temperature (A) within the vitreous body and (B) on the cornea was continuously measured during irradiation (mean $\pm S D$; $n=3$; n.s. not significant, ${ }^{*} p<0.05,{ }^{* *} p<0.01$; one way ANOVA).

\subsection{Retina explants of adult and postnatal mice withstand temperature exposure up to $40^{\circ} \mathrm{C}$}

Irradiation of perfused pig eyes revealed a strong dose-dependent increase in vitreal temperature. Since an increase of temperature within the vitreous body may be associated with elevated temperature of the neighboring retinal tissue, we further analyzed the impact of hyperthermia on the expression levels of general molecular markers of cytotoxicity in the retina. Briefly, retinal explants of mice were exposed to $40{ }^{\circ} \mathrm{C}$ for $30 \mathrm{~min}$ in the presence or absence of wIRA/VIS at $1000 \mathrm{~W} / \mathrm{m}^{2}$. Retinae of both adult and postnatal mice (10 days, P10) were used for the experiment since the latter corresponds with the retinal developmental stage of human neonates and infants. Measuring the levels of phosphorylated stress kinases p38, Akt, Erk 1/2 and SAPK/JNK by ELISA, we observed no significant changes immediately $(0 \mathrm{~h}), 3 \mathrm{~h}$ or $24 \mathrm{~h}$ following treatment in retinae of adult mice (Figure 5A). The only increase observed were the pSAPK/JNK levels by a factor of 1.9 immediately after both $40{ }^{\circ} \mathrm{C}$ alone and in combination with irradiation in the retinae of postnatal mice (Figure 5B). At the later time points ( $3 \mathrm{~h}$ and $24 \mathrm{~h}$ ), no changes in the level of stress kinases were observed in either adult or postnatal retinae (Figure 5). 


\section{A) Adult}

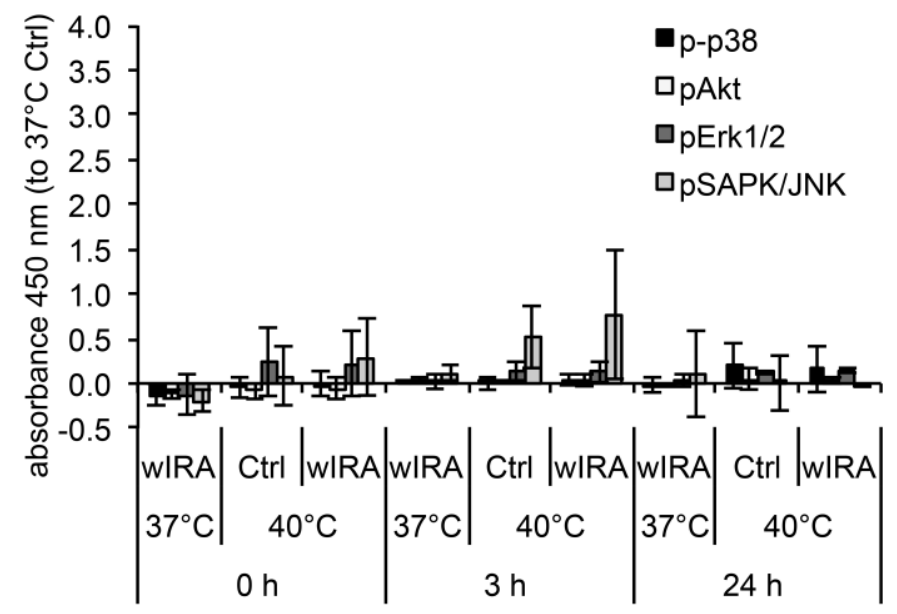

\section{B) Postnatal}

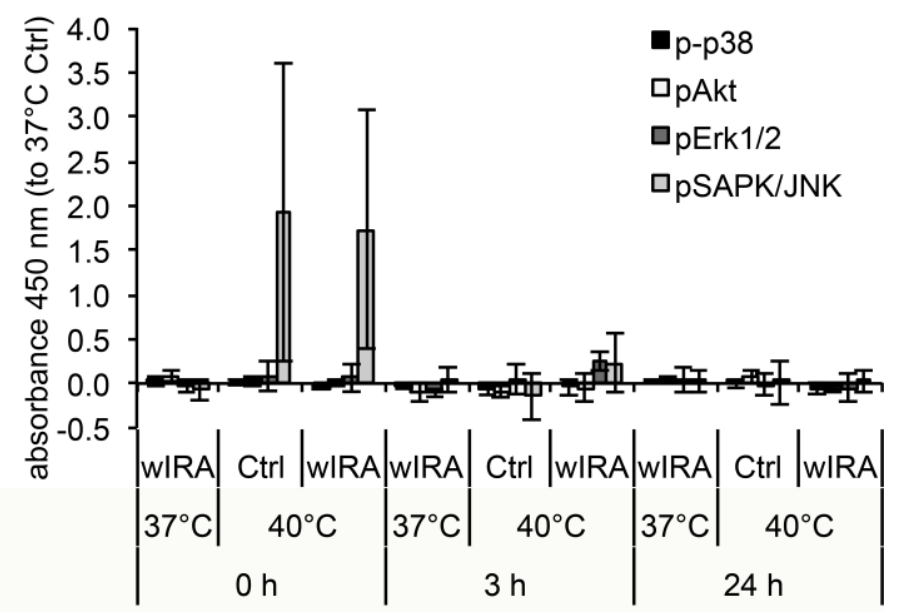

Figure 5. Levels of general and molecular markers of cytotoxicity are unaffected by both hyperthermia alone or in combination with irradiation in adult and postnatal mouse retina except for a rapid increase of pSAPK/JNK in the postnatal retina. (1 column)

Retinal explants of $(A)$ adult or (B) postnatal mice (P10) were irradiated with wIRA and visible light (BTE $595,1000 \mathrm{~W} / \mathrm{m}^{2}$ ) for $30 \mathrm{~min}$. Temperature was adjusted to 37 or $40{ }^{\circ} \mathrm{C}$ during the irradiation process. Tissues were subsequently collected after $0 \mathrm{~h}, 3 \mathrm{~h}$ and $24 \mathrm{~h}$ at $37^{\circ} \mathrm{C}$. Measurements for the levels of $\mathrm{p}-\mathrm{p} 38, \mathrm{pAkt}, \mathrm{pErk1/2}$ and pSAPK/JNK by ELISA assay are shown. Values are normalized to the $37^{\circ} \mathrm{C}$ control values (mean $\pm \mathrm{SD} ; \mathrm{n}=3$ ).

\subsection{Cell viability is not reduced following irradiation}

Determination of cell viability is an important in vitro parameter to detect potentially harmful effects of a treatment method. In a previous study, we showed that the viability of permanent cell lines (HeLa, Vero) was not negatively affected by wIRA/VIS even after long-term treatment for more than four 
hours up to one day after exposure (20). In order to exclude possible damaging effects of wIRA and wIRA/VIS irradiation to the primary conjunctival cell line $\mathrm{HCjE}$, we measured the cell viability post treatment using two different methods.

First, cell metabolism was assessed with the AlamarBlue assay after single-dose or four times irradiation of $\mathrm{HCjE}$ by adding $10 \%$ AlamarBlue immediately after the last treatment and processing the samples as described in 2.7.1. We found that irradiation of $\mathrm{HCjE}$ with wIRA alone led to a slight reduction in cell viability to $86.99 \%( \pm 3.96 \%)$ and $78.54 \%( \pm 8.67 \%)$ of the control value after single and four times irradiation, respectively, which was significant in both cases $(p=0.0432$ after single, $p$ $=0.0488$ after four times irradiation, Figure $6 \mathrm{~A}$ ). However, wIRA/VIS did not significantly reduce the cell viability, with reductions to $95.37 \% \pm 0.65 \%$ for single $(p=0.0525)$ and $88.13 \% \pm 6.38 \%$ for four times irradiation versus control values $(p=0.0999$, Figure 6B).

Second, we calculated the mean number of cells per high-power field in order to identify possible cell loss due to treatment. There was no significant decrease in the average number of cells in irradiated $\mathrm{HCjE}$ compared to non-irradiated $\mathrm{HCjE}$ regardless of treatment. In detail, we found that wIRA alone and wIRA/VIS were associated with 21.67 cells/field \pm 5.33 and 21.67 cells/field \pm 2.04 , respectively, compared to the non-irradiated control with 21.48 cells/field \pm 2.69 following single-dose irradiation (Figure 6C). Similarly, after irradiating HCjE four times, the number of cells per field was $22.5 \pm 0.78$ for wIRA/VIS and $21.73 \pm 2.41$ for wIRA alone. Non-irradiated cultures yielded 21.33 cells/field \pm 1.21 (Figure 6D). 
A) AlamarBlue (1x irradiation)

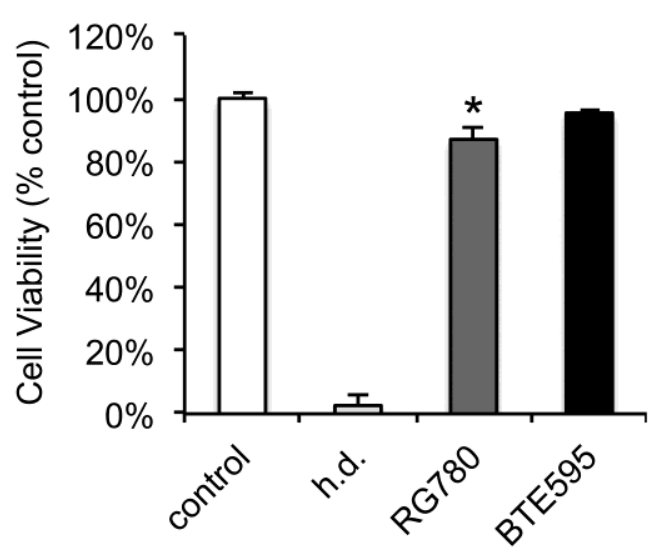

C) Cells/Field (1x irradiation)

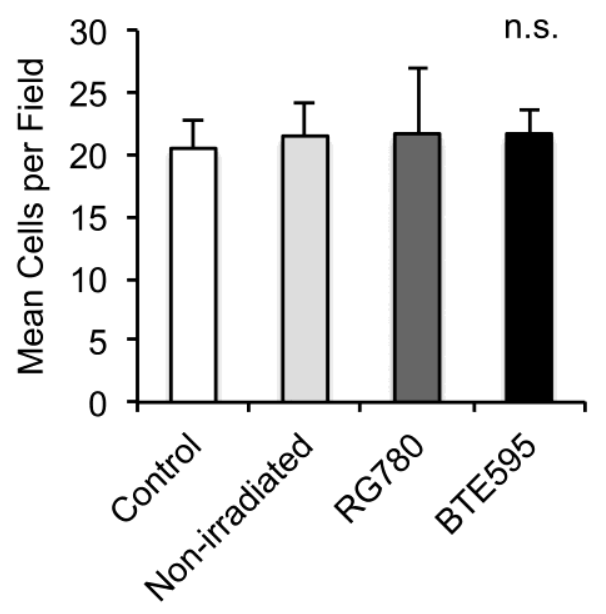

B) AlamarBlue (4x irradiation)

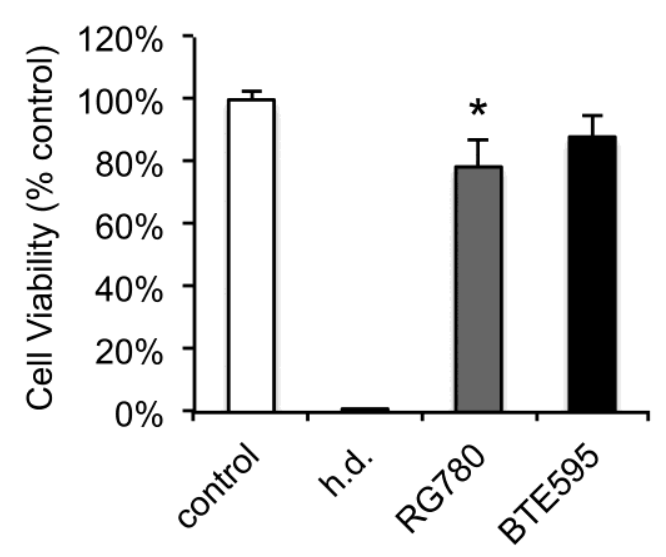

D) Cells/Field (4x irradiation)

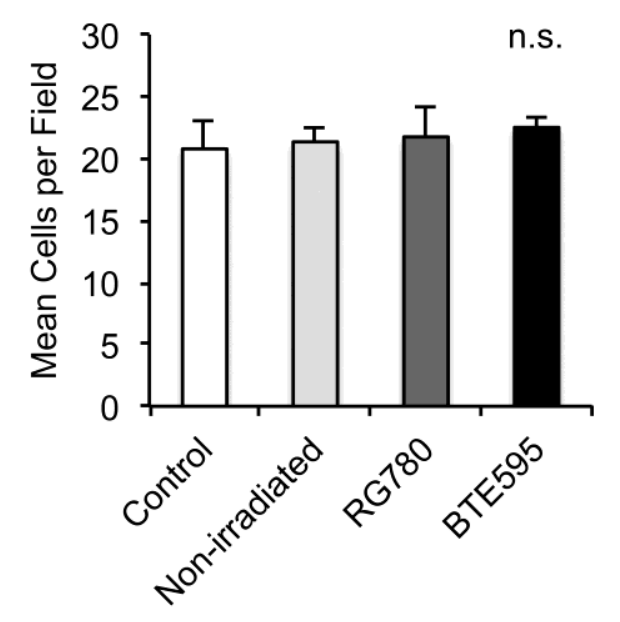


409 (A-B) present the results of the AlamarBlue assay as mean $\pm S D\left(n \geq 2 ; t\right.$ test, $\left.{ }^{*} p>0.05\right)$. Briefly, 10 $410 \%$ AlamarBlue dye was added to the medium for three hours immediately after irradiating HCjE (A) 411 once or (B) four times with either wIRA alone (RG 780 filter, $2000 \mathrm{~W} / \mathrm{m}^{2}$ ) or WIRA and visible light 412 (BTE 595, $2100 \mathrm{~W} / \mathrm{m}^{2}$ ) for 30 min per treatment. Heat-denatured samples (h.d.) were included as 413 killing controls. For (C-D), the number of nuclei per field at 1000x magnification was evaluated in 10 414 fields per condition 43 hours post infection (hpi) with C. trachomatis serotype B. Shown is the mean 415 number of nuclei following (C) single-dose irradiation $40 \mathrm{hpi}$, or (D) after irradiation $8 \mathrm{~h}, 6 \mathrm{~h}, 3 \mathrm{~h}$ and 416 immediately prior infection (mean $\pm \mathrm{SD}$; n.s. not significant; $\mathrm{n} \geq 3$; $t$ test). Non-infected and non417 irradiated $\mathrm{HCjE}$ cultures were used as control. Each irradiation was applied for 30 min with either 418 wIRA alone (RG 780, $2000 \mathrm{~W} / \mathrm{m}^{2}$ ) or wIRA and visible light (BTE 595, $2100 \mathrm{~W} / \mathrm{m}^{2}$ ). 


\subsection{Chlamydial infectivity is reduced following single-dose irradiation of mature chlamydial} infections in $\mathrm{HCjE}$

We have previously established that infections with the genital $C$. trachomatis serovar $E$ strain or $C$. pecorum isolated from a swine abortion were significantly inhibited when wIRA/VIS (380-1400 nm) or wIRA alone (780-1400 nm) was applied $40 \mathrm{~h}$ post infection of HeLa or Vero cells, regardless of the infectious dose and the radiation spectrum $(20,21)$. We wished to confirm these results by investigating the effects of wIRA alone or wIRA with a partial visible light spectrum $(595-780 \mathrm{~nm}$, BTE 595) on mature chlamydial inclusions in $\mathrm{HCjE}$. For this purpose, we infected monolayers with $\mathrm{C}$. trachomatis B EBs, irradiated them at $40 \mathrm{hpi}$ for $30 \mathrm{~min}$, and collected samples three hours later for titration by sub-passage as described in 2.11. Cultures were infected with doses of $\mathrm{MOI} 0.1$ (Figure 7) and MOI 1.0 (Figure S1A) and irradiated with wIRA/VIS or wIRA alone at $2100 \mathrm{~W} / \mathrm{m}^{2}$ and $2000 \mathrm{~W} / \mathrm{m}^{2}$, respectively.

Surprisingly, we found that while wIRA alone reduced the infectivity of mature chlamydial inclusions by $35.27 \%( \pm 8.16 \%$ ) (Figure $7 \mathrm{~A})$, wIRA/VIS reduced it by $53.81 \% \pm 4.62 \%$ at MOI 0.1 (Figure $7 \mathrm{~B}$ ). The difference between the two irradiation spectra was significant $(p=0.0298)$. In contrast, there was no significant difference between the two infectious doses (MOI $0.1,1)$ following treatment with wIRA alone $(p=0.721$, Figure $\mathrm{S} 1 \mathrm{~A})$.

436

\section{A) WIRA}

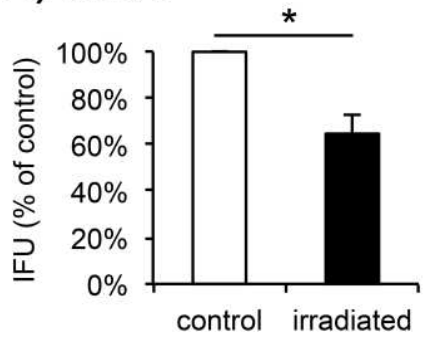

B) WIRA/VIS

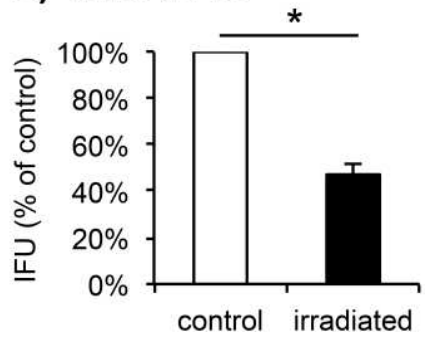

Figure 7. Infectivity is reduced following single-dose irradiation of mature chlamydial infections in HCjE. ( 1 column)

$\mathrm{HCjE}$ were infected with $C$. trachomatis serotype $\mathrm{B}$ at $\mathrm{MOI} 0.1$ and irradiated or not 40 hours post infection (hpi) for 30 min with (A) wIRA alone (RG 780, $2000 \mathrm{~W} / \mathrm{m}^{2}$ ) or (B) wIRA and visible light (BTE $\left.595,2100 \mathrm{~W} / \mathrm{m}^{2}\right)$. Cultures were collected at $43 \mathrm{hpi}$ for titration by sub-passage. Inclusion-forming units per $\mathrm{mL}\left(\mathrm{IFU} / \mathrm{mL}\right.$ ) are shown as percent of non-irradiated controls (mean $\pm \mathrm{SD}$; ${ }^{*} \mathrm{p}<0.05 ; \mathrm{n}=3$; $t$ test). 


\subsection{Irradiation of EBs and cells prior to infection enhances the anti-chlamydial effect} In previous publications $(20,21)$, we showed that irradiation of $C$. pecorum and $C$. trachomatis E EBs prior to infection of either Vero or HeLa cells led to reduced chlamydial infectivity. In this study, we wished to confirm these findings in an eye infection model by subjecting $C$. trachomatis B EBs to wIRA alone $\left(2000 \mathrm{~W} / \mathrm{m}^{2}\right)$ and wIRA/VIS $\left(2100 \mathrm{~W} / \mathrm{m}^{2}\right)$ for $30 \mathrm{~min}$ before infection of $\mathrm{HCjE}$. In addition, we further investigated the effect of treating cells alone or in combination with EB treatment by irradiating cells $8 \mathrm{~h}, 6 \mathrm{~h}, 3 \mathrm{~h}$ and immediately prior to infection with irradiated or nonirradiated EBs, which resulted in four conditions for both radiation spectra: a) non-irradiated cells infected with non-irradiated EBs (control, E-C-), b) irradiated cells infected with non-irradiated EBs (E$\mathrm{C}+), \mathrm{c})$ non-irradiated cells infected with irradiated $\mathrm{EBs}(\mathrm{E}+\mathrm{C}-)$ and d) irradiated cells infected with irradiated $\mathrm{EBs}(\mathrm{E}+\mathrm{C}+)$.

We found that irradiating both EBs and cells led to the strongest decrease in infectivity compared to non-irradiated controls for both wIRA alone and wIRA/VIS, with decreases to $73.54 \% \pm 0.55 \%$ (Figure $8 \mathrm{~A}$ ) and $86.85 \% \pm 0.92 \%$ (Figure $8 \mathrm{~B}$ ) of the control, respectively. Next, irradiation of EBs alone led to a strong reduction in the infectivity of EBs, especially in the presence of a visible light component (wIRA alone: $45.73 \% \pm 7.80 \%$, wIRA/VIS: $30.54 \% \pm 2.96 \%$ of non-irradiated controls). However, treatment of only $\mathrm{HCjE}$ prior to infection also led to a significant reduction in chlamydial infectivity post infection for both wIRA alone $(35.37 \% \pm 1.53 \%)$ and in combination with visible light (wIRA/VIS, $33.96 \% \pm 1.54 \%$ ) versus controls. Interestingly, while the effect of irradiating cells with wIRA alone compared to wIRA/VIS was not significantly different $(p=0.3235)$, wIRA/VIS led to a significantly more efficient reduction compared to wIRA alone for both EB treatment $(p=0.0344)$ and the combination treatment of both EBs and cells $(p<0.0001)$. Similarly to treatment of mature chlamydial inclusions (3.5) and previous studies (21), there was no significant difference between the infectivity of EBs at MOI $1(39.95 \% \pm 7.94 \%$ to non-irradiated control) and MOI $0.1(42.25 \% \pm 10.68$ $\%)$ after irradiation with wIRA alone (Figure S1B). 


\section{A) WIRA}

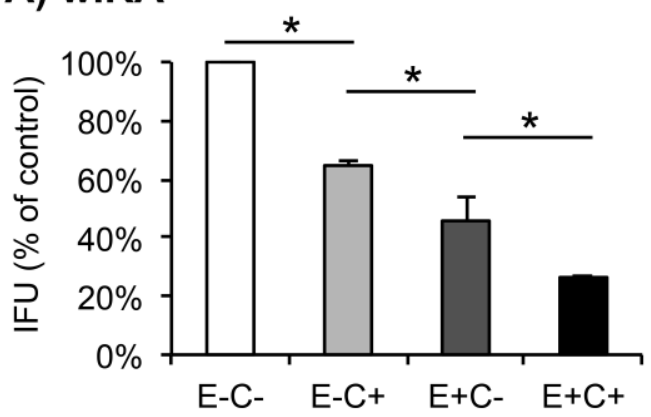

\section{B) WIRA/VIS}

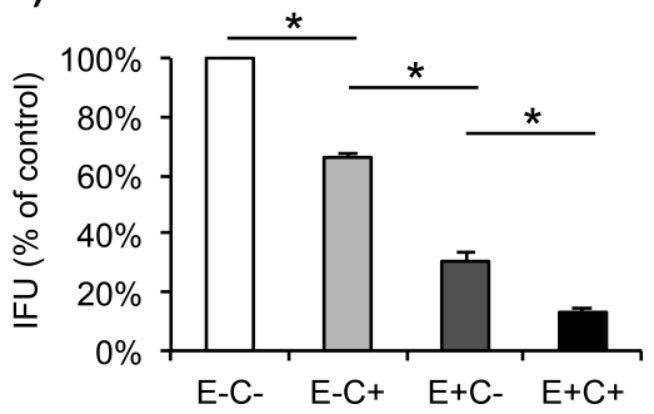

472

473

474

475

Figure 8. Irradiation of $C$. trachomatis $\mathrm{B} \mathrm{EBs}$ and $\mathrm{HCjE}$ prior to infection enhances the antichlamydial effect. (1.5 columns)

HCjE were irradiated $\left(\mathrm{C}^{+}\right)$or not $(\mathrm{C}-)$ four times $8 \mathrm{~h}, 6 \mathrm{~h}, 3 \mathrm{~h}$ and immediately prior to infection with irradiated $(\mathrm{E}+)$ or non-irradiated $(\mathrm{E}-)$ C. trachomatis serotype $\mathrm{B}$ EBs. After $43 \mathrm{~h}$ of incubation, cultures were collected for titration by sub-passage. Shown is the mean $\pm S D\left({ }^{*} p<0.05 ; n \geq 3 ; t\right.$ test) of inclusion-forming units per $\mathrm{mL}$ (IFU/mL) as percent of a non-irradiated control (E-C-). Each irradiation treatment was performed for 30 min either with (A) wIRA alone (RG $780,2000 \mathrm{~W} / \mathrm{m}^{2}$ ) or (B) wIRA in combination with visible light (BTE 595, $2100 \mathrm{~W} / \mathrm{m}^{2}$ ).

\section{Discussion}

Blinding trachoma is still endemic in many parts of the world even though the WHO has been combating the disease since 1997 (1-4). To date, antibiotic treatment as part of the SAFE strategy has not produced the desired results, leaving a considerable number of people still infected despite therapy $(4,5)$. This being the case, the aim of our study was to develop a possible new, non-chemical treatment method for trachoma patients using near-infrared A radiation. This approach was evaluated by using an in vitro infection cell culture model and two ex vivo eye models.

Since the eye is one of the most photosensitive organs, careful examination of the eye during and after irradiation treatment is crucial to exclude any damage or unwanted side effects. It is known that wIRA has a thermal component $(18,20,37)$, which prompted us to examine temperature during 30 min of irradiation with either wIRA or wIRA/VIS in perfused pig eyes. The initial temperature was set to 34 ${ }^{\circ} \mathrm{C}$ to represent the physiological in vivo eye temperature. Temperature measurements within the eye are challenging and reports of ocular temperature in the literature show variable results. SalcedoVillanueva et al. determined a mean vitreous temperature in human eyes of $33.04{ }^{\circ} \mathrm{C}$ during cataract surgery (38), while Landers et al. found the mid-vitreous temperature to be between 33.2 and $34.7^{\circ} \mathrm{C}$ 
(34). The temperature was similar in anaesthetized pigs, reporting a mean of $34.7-35.8{ }^{\circ} \mathrm{C}$ for the vitreous body and $34.3{ }^{\circ} \mathrm{C}$ for the aqueous chamber. Temperature near the retina was found to be slightly higher $\left(34.4-35.3^{\circ} \mathrm{C}\right)$ as it contains blood vessels and is consequently influenced by the body temperature (36).

In our ex vivo model of perfused pig eyes, we found that the corneal temperature never exceeded 35 ${ }^{\circ} \mathrm{C}$ at radiation doses of $2000 \mathrm{~W} / \mathrm{m}^{2}$ wIRA and $2100 \mathrm{~W} / \mathrm{m}^{2} \mathrm{wIRA} / \mathrm{VIS}$. Since the vitreal temperature after irradiation with the dose of $2100 \mathrm{~W} / \mathrm{m}^{2}$ was $37{ }^{\circ} \mathrm{C}$, which equals the physiological body temperature, we chose this dose as a potential therapeutic radiation dose and used it in all further experiments. The temperature difference between irradiation with wIRA and irradiation with wIRA/VIS on the cornea was not significant. The only slight temperature elevation in our ex vivo model is a promising result regarding possible future administration in vivo. However, the actual in vivo temperature could be different, given the fact that the cornea is an avascular tissue. Thus corneal temperature depends on the temperature of the eye lids, while the lids are closing, and on the ambient temperature as well as the aqueous temperature when the eye is opened (39). Similar results were obtained in the cell culture experiments. Even though the initial intra-well temperature was slightly higher with wIRA alone, there was no significant difference amongst the filters after the irradiation period of $30 \mathrm{~min}$. In contrast to these findings, the final temperature inside the vitreous body was significantly higher following irradiation with wIRA alone compared to irradiation with wIRA/VIS. A possible explanation for this could be that the vitreous body was the only closed system in our experiments, thus accumulating heat energy, whereas cornea and wells were exposed to ambient temperature. Several studies have aimed to evaluate consequences of increased temperatures on ocular structures. Some authors claimed that hyperthermia induced by infrared radiation may lead to cataract formation $(40,41)$, while Wolbarsht hypothesized that this process was not thermal but photochemically-induced (42). In a more recent publication, Yu et al. performed in vivo experiments with rats and found that exposure to $197 \mathrm{~W} / \mathrm{cm}^{2}$ 1090-nm infrared reflectrography (IRR) for eight seconds led to a temperature increase of $10{ }^{\circ} \mathrm{C}$ at the limbus and $26{ }^{\circ} \mathrm{C}$ near the retina, which induced cataract (43). However, Yu et al. used a laser as a source for IRR, which contains more heat radiation. In wIRA, part of the heat energy is filtered through the water cuvette (16), so heating of the tissue should be rather moderate. 
The retina belongs to the main structures of the eye, which converts electromagnetic radiation into neuronal signals (44). In order to exclude damage following wIRA treatment, we exposed retina explants of postnatal and adult mice to different temperatures of up to $40{ }^{\circ} \mathrm{C}$ with or without the combination of wIRA irradiation and measured the expression of general and molecular cytotoxicity markers. No changes regarding expression levels in adult retinae were observed, even in samples with temperature treatment of $40^{\circ} \mathrm{C}$ in combination with wIRA. In retinal tissue of postnatal mice only the levels of pSAPK/JNK were increased directly after treatment with temperature alone and in combination with wIRA. These results suggest that even in a highly vulnerable model, there is no significant increase in the level of observed stress markers of the retina after wIRA application or temperature exposure up to $40^{\circ} \mathrm{C}$. Iwami et al. recently described a laser-induced temperature of 50 $52{ }^{\circ} \mathrm{C}$ to be the threshold for retinal pigment epithelium (RPE) cell death. Moreover, they observed that sub-lethal temperatures of about $43{ }^{\circ} \mathrm{C}$ increase cell defense mechanisms against oxidative stress (45). These mechanisms can be induced by hyperthermia (46). Though, as mentioned before, these temperatures of lethal hyperthermia are not expected during wIRA exposure (16).

Cell viability following wIRA irradiation was further examined in vitro. Previously, we demonstrated that wIRA/VIS does not reduce cell metabolism of HeLa or Vero cells, nor were there any signs of cytotoxicity in HeLa cells (20). In our recent experiments, metabolism of the conjunctival cell line HCjE was only slightly reduced using the highest achievable dose of wIRA without visible light. However, irradiation with wIRA/VIS did not result in any considerable decrease of metabolic activity compared to the non-irradiated controls after single or four times irradiation for $30 \mathrm{~min}$. We hypothesized that since $\mathrm{HCjE}$ is a healthy cell line, they are probably more susceptible to stressors than cell lines from a cancerous origin such as HeLa, possibly explaining the slight viability decrease after irradiation with wIRA alone. A recent study supports our findings, stating that metabolic activity was even enhanced after wIRA irradiation in another continuous cell line (47). Knels et al. irradiated Swiss albino mouse embryonic fibroblast cell-line NIH/3T3 cultures with $300 \mathrm{~W} / \mathrm{m}^{2}$ (WIRA, 780-1400 nm) for either 60 or 120 min demonstrating that the overall metabolic rate was increased post irradiation. Furthermore, it was significantly higher in all samples at $40^{\circ} \mathrm{C}$ regardless of wIRA treatment compared to samples at $37^{\circ} \mathrm{C}$.

Furthermore we could not detect any cell loss in $\mathrm{HCjE}$ monolayers irradiated either with wIRA or wIRA/VIS by enumerating nuclei per microscopic field as another indicator for potential cytotoxic effects. 
Based on our previous studies with C. pecorum in Vero cells and C. trachomatis $\mathrm{E}$ in HeLa cells, we established a trachoma infection model using the ocular strain C. trachomatis $\mathrm{B}$ in $\mathrm{HCjE}$ cells and irradiated samples at 40 hours post infection. The reduction of chlamydial infectivity was significant with both filters and similar to the results of previous experiments $(20,21)$. The reduced infectivity following treatment with wIRA alone was not influenced by the chlamydial infection dose (MOI 0.1, 1). Interestingly, in cultures infected with only $\mathrm{MOI} 0.1$, irradiation with wIRA/VIS decreased the chlamydial infectivity more efficiently than wIRA alone. However, in our previous study with cancerous cell lines (21), we did not see any additional reducing effect of VIS on mature chlamydial inclusions, hence this outcome could again be dependent on the characteristics of the non-cancerous cell line. The impact of VIS was further analyzed in another experiment, in which we irradiated EBs and $\mathrm{HCjE}$ prior to infection. Here we demonstrated that the relative decrease in chlamydial infectivity was significantly higher following treatment of EBs with wIRA/VIS compared to wIRA alone, which is in accordance with our previous findings (21). In addition, the visible light component had no significant influence on the chlamydial infectivity if only cells were irradiated prior infection leading to the conclusion that extracellular C. trachomatis B EBs are sensitive to visible light.

573 Furthermore we found that, independent of the visible light component, the highest decrease of chlamydial infectivity occurred if both EBs and cells were irradiated prior infection. Surprisingly, the number of chlamydial inclusions was also reduced following irradiation of uninfected $\mathrm{HCjE}$ alone without any direct treatment of Chlamydia leading us to hypothesize that a wIRA-induced cellular protective effect is stimulated against subsequent chlamydial infection. According to several other studies, this might be due to an increased cell metabolism (16-19). Knels et al. recently discovered that wIRA irradiation of fibroblast cultures not only enhances metabolic activity, but also that it has a protective effect on cells, improving their viability under oxidative stress. The authors consider a possible beneficial effect on mitochondria (47).

In summary, we demonstrate that irradiation with wIRA/VIS or wIRA alone reduces chlamydial infectivity in primary human conjunctival epithelial cells infected with the trachoma strain $C$. trachomatis $\mathrm{B}$ at doses not reducing the cell viability. The required wIRA doses, which trigger this effect, cause only physiological temperatures on the cornea and in the vitreous body of perfused pig eyes. However, since these structures directly neighbor the retina, we further analyzed possible effects of hyperthermia on this neuronal tissue. 
589 (MAPK) and also the Akt pathway in parts of the brain (48), we elucidated the phosphorylation levels of p38 MAPK, Erk, JNK and Akt in the retina of adult and postnatal mice after $30 \mathrm{~min}$ of $40{ }^{\circ} \mathrm{C}$. Except for the postnatal retina, we failed to detect significant changes in the activation of these stress related pathways, which indicates a lack of degenerative stimuli after this treatment, at least in the adult situation. In particular, our results show that the addition of VIS contributes to the antimicrobial effect of this nonchemical method. EBs appear to be highly sensitive to exposure to the visible light component specifically. There was also a greater reduction in the infectivity of mature chlamydial inclusions following exposure to wIRA/VIS compared to wIRA alone. Interestingly, the temperature increase in the vitreous body of pig eyes following wIRA/VIS exposure was less pronounced compared to irradiation with wIRA alone, leading us to conclude that, in addition to an already described irradiation dose effect, the radiation spectrum $(780-1400 \mathrm{~nm}, 595-1400 \mathrm{~nm})$ may additionally influence the effect of irradiation on chlamydial infection and tissue. We failed to observe wIRA-induced damage of $\mathrm{HCjE}$ or retinal tissue. Instead, we discovered a possible beneficial cellular effect, suggesting that near-infrared radiation with or without visible light triggers cell mechanisms that protect the cell from chlamydial infections. Our study is the first of its kind demonstrating that near-infrared $A$ radiation reduces chlamydial infections in primary human conjunctival epithelial cells in vitro without corresponding negative consequences in ex vivo models, providing the basis to introduce irradiation as a potential non-chemical method to treat trachoma. 
609 We would like to thank Theresa Pesch of the Institute of Veterinary Pathology Zurich for her excellent

610 technical assistance in the cell culture laboratory. Furthermore, we greatly appreciate the transfer of $C$.

611 trachomatis B strain and HCjE from the Medical University of Vienna as well as the donation of LLC-

612 MK2 cells by Manuela Donati, University of Bologna. We also would like to thank Werner Müller and

613 Eduard Wolf for instructions using the equipment for wIRA irradiation as well as for their supporting

614 information about physical aspects.

615 Finally we would like to thank the Dr. Erwin Braun Foundation, Basel, Switzerland for providing 616 funding for this project. 


\section{References}

618 1. Burton MJ, Rajak SN, Bauer J, Weiss HA, Tolbert SB, Shoo A, et al. Conjunctival transcriptome in scarring trachoma. Infect Immun. Am Soc Microbiol; 2011;79(1):499-511.

2. WHO. Global WHO Alliance for Elimination of Blinding Trachoma. Wkly Epidemiol Rec. 2013;88:241-6.

3. WHO. WHO Alliance for the Global Elimination of Blinding Trachoma by the year 2020. Progress report on elimination of trachoma, 2013. Wkly Epidemiol Rec. 2014;89(39):421-8.

4. WHO. Report of the 17th meeting of the WHO alliance for the global elimination of blinding trachoma. [Internet]. 2013. Available from: www.who.int/blindness/publications/GET17Report_final.pdf?ua=1

5. West SK, Moncada J, Munoz B, Mkocha H, Storey P, Hardick J, et al. Is there evidence for resistance of ocular Chlamydia trachomatis to azithromycin after mass treatment for trachoma control? J Infect Dis [Internet]. 2014 Jul 1 [cited 2016 Mar 8];210(1):65-71. Available from: http://jid.oxfordjournals.org/cgi/content/long/210/1/65

6. U.S. Department of Health and Human Services. Antibiotic Resistance Treats in the United States, 2013 [Internet]. 2013. Available from: www.cdc.gov/drugresistance/pdf/ar-threats-2013-

7. Andersen AA, Rogers DG. Resistance to tetracycline and sulfadiazine in swine C. trachomatis

8. Dugan J, Rockey DD, Jones L, Andersen AA. Tetracycline resistance in Chlamydia suis mediated by genomic islands inserted into the chlamydial inv-like gene. Antimicrob Agents

9. Borel N, Regenscheit N, Di Francesco A, Donati M, Markov J, Masserey Y, et al. Selection for tetracycline-resistant Chlamydia suis in treated pigs. Vet Microbiol. Elsevier; 2012;156(1):1436. isolates. In: Chlamydial infections Proceedings of the Ninth International Symposium on Human Chlamydial Infection International Chlamydia Symposium, San Francisco, Ca. 1998. p. 313-6. Chemother. Am Soc Microbiol; 2004;48(10):3989-95.

Donati M, Balboni A, Laroucau K, Aaziz R, Vorimore F, Borel N, et al. Tetracycline Susceptibility in Chlamydia suis Pig Isolates. PLoS One [Internet]. Public Library of Science; 2016 Jan 25 [cited 2016 Mar 24];11(2):e0149914. Available from: http://dx.doi.org/10.1371/journal.pone.0149914 
11. Borel N, Leonard C, Slade J, Schoborg RV. Chlamydial Antibiotic Resistance and Treatment Failure in Veterinary and Human Medicine. Curr Clin Microbiol Reports. 2016;3(1):10-8.

12. Hoffmann K, Schott F, Donati M, Di Francesco A, Hässig M, Wanninger S, et al. Prevalence of Chlamydial Infections in Fattening Pigs and Their Influencing Factors. Ojcius DM, editor. PLoS One [Internet]. San Francisco, CA USA: Public Library of Science; 2015 Nov 30;10(11):e0143576. Available from: http://www.ncbi.nlm.nih.gov/pmc/articles/PMC4664257/

13. Schautteet K, Vanrompay D. Chlamydiaceae infections in pig. Vet Res [Internet]. BioMed Central; 2011 Feb 7;42(1):29. Available from:

http://www.ncbi.nlm.nih.gov/pmc/articles/PMC3041669/

14. Suchland RJ, Sandoz KM, Jeffrey BM, Stamm WE, Rockey DD. Horizontal Transfer of Tetracycline Resistance among Chlamydia spp. In Vitro . Antimicrob Agents Chemother [Internet]. American Society for Microbiology (ASM); 2009 Nov 17;53(11):4604-11. Available from: http://www.ncbi.nlm.nih.gov/pmc/articles/PMC2772348/

15. Dean D, Rothschild J, Ruettger A, Kandel RP, Sachse K. Zoonotic Chlamydiaceae Species Associated with Trachoma, Nepal. Emerg Infect Dis [Internet]. Centers for Disease Control and Prevention; 2013 Dec;19(12):1948-55. Available from:

http://www.ncbi.nlm.nih.gov/pmc/articles/PMC3840858/

16. Hoffmann G. Principles and working mechanisms of water-filtered infrared-A (wIRA) in relation to wound healing. GMS Krankenhhyg Interdiszip. 2007;2(2):54.

17. Künzli BM, Liebl F, Nuhn P, Schuster T, Friess H, Hartel M. Impact of preoperative local waterfiltered infrared $\mathrm{A}$ radiation on postoperative wound healing: a randomized patient- and observer-blinded controlled clinical trial. Ann Surg. 2013;258(6):887-94.

18. Hartel M, Hoffmann G, Wente MN, Martignoni ME, Büchler MW, Friess H. Randomized clinical trial of the influence of local water-filtered infrared A irradiation on wound healing after abdominal surgery. Br J Surg [Internet]. John Wiley \& Sons, Ltd.; 2006 Aug 1;93(8):952-60. Available from: http://dx.doi.org/10.1002/bjs.5429

19. Hoffmann G. Water-filtered infrared-A (wIRA) in acute and chronic wounds. GMS Krankenhhyg Interdiszip. 2009;4(2):12.

20. Marti H, Koschwanez M, Pesch T, Blenn C, Borel N. Water-filtered infrared a irradiation in combination with visible light inhibits acute chlamydial infection. Dean D, editor. PLoS One [Internet]. Public Library of Science; 2014 Jan [cited 2016 Feb 22];9(7):e102239. Available 
from: http://dx.plos.org/10.1371/journal.pone.0102239

21. Marti $\mathrm{H}$, Blenn $\mathrm{C}$, Borel $\mathrm{N}$. The contribution of temperature, exposure intensity and visible light to the inhibitory effect of irradiation on acute chlamydial infection. J Photochem Photobiol B [Internet]. 2015 Dec [cited 2016 Feb 22];153:324-33. Available from:

http://www.sciencedirect.com/science/article/pii/S1011134415003334

22. Kels BD, Grzybowski A, Grant-Kels JM. Human ocular anatomy. Clin Dermatol [Internet]. 2015 Jan [cited 2016 Mar 31];33(2):140-6. Available from:

http://www.sciencedirect.com/science/article/pii/S0738081X1400234X

23. Guduric-Fuchs J,, Ringland JL., Gu P, Dellett M, Archer DB, Cogliati T. Immunohistochemical study of pig retinal development. Mol Vis. 2009;15:1915-28.

24. Yanai A, Laver C R, Gregory-Evans C Y, Liu RR, Gregory-Evans K. Enhanced functional integration of human photoreceptor precursors into human and rodent retina in an ex vivo retinal explant model system. Tissue Eng Part A. 2015;21:1763-71.

25. Johnson TV, Martin KR. Development and Characterization of an Adult Retinal Explant Organotypic Tissue Culture System as an In Vitro Intraocular Stem Cell Transplantation Model. Invest Ophthalmol Vis Sci [Internet]. 2008 Aug 1;49(8):3503-12. Available from: http://dx.doi.org/10.1167/iovs.07-1601

26. Hoerster R, Muether PS., Vierkotten S, Schröder S, Kirchhof B, Fauser S. In-vivo and ex-vivo characterization of laser-induced chronical neovascularization variability in mice. Graefes Arch Clin Exp Ophthalmol. 2012;250(11):1579-86.

27. Wilson WS, Shahidullah M, Millar C. The bovine arterially-perfused Eye: An in vitro method for the study of drug mechanisms on IOP, aqueous humor formation and uveal vasculature. Curr Eye Res. 1993;12(7):609-20.

28. Shahidullah M, Wilson WS, Yap M, To CH. Effects of ion transport and channel-blocking drugs on aqueous humor formation in isolated bovine eye. Invest Ophthalmol Vis Sci. 2003;44(3):1185-91.

29. Frohns A, Frohns F, Naumann SC, Layer PG, Löbrich M. Inefficient double-strand break repair in murine rod photoreceptors with inverted heterochromatin organization. Curr Biol [Internet]. Elsevier; 2014 May 19 [cited 2016 May 30];24(10):1080-90. Available from: http://www.cell.com/article/S0960982214003534/fulltext

30. Gipson IK, Spurr-Michaud S, Argüeso P, Tisdale A, Ng TF, Russo CL. Mucin gene expression 
in immortalized human corneal-limbal and conjunctival epithelial cell lines. Invest Ophthalmol Vis Sci. The Association for Research in Vision and Ophthalmology; 2003;44(6):2496-506.

31. Marangoni A, Bergamini C, Fato R, Cavallini C, Donati M, Nardini P, et al. Infection of human monocytes by Chlamydia pneumoniae and Chlamydia trachomatis: an in vitro comparative

32. Deka S, Vanover J, Dessus-Babus S, Whittimore J, Howett MK, Wyrick PB, et al. Chlamydia trachomatis enters a viable but non-cultivable (persistent) state within herpes simplex virus type 2 (HSV-2) co-infected host cells. Cell Microbiol [Internet]. Blackwell Science Ltd; 2006 Jan 1;8(1):149-62. Available from: http://dx.doi.org/10.1111/j.1462-5822.2005.00608.x

33. Borel N, Dumrese C, Ziegler U, Schifferli A, Kaiser C, Pospischil A. Mixed infections with Chlamydia and porcine epidemic diarrhea virus - a new in vitro model of chlamydial persistence. BMC Microbiol [Internet]. 2010;10(1):1-9. Available from: http://dx.doi.org/10.1186/1471-2180-10-201

34. Landers MB, Watson JS, Ulrich JN, Quiroz-Mercado H. Determination of retinal and vitreous temperature in vitrectomy. Retina. 2012;32(1):172-6.

35. Sniegowski M, Erlanger M, Velez-Montoya R, Olson JL. Difference in ocular surface temperature by infrared thermography in phakic an pseudophakic patients. Clin Ophthalmol [Internet]. Dove Medical Press; 2015 Mar 9;9:461-6. Available from: http://www.ncbi.nlm.nih.gov/pmc/articles/PMC4358693/

36. Lorget F, Parenteau A, Carrier M, Lambert D, Gueorguieva A, Schuetz C, et al. Characterization of the $\mathrm{pH}$ and Temperature in the Rabbit, Pig, and Monkey Eye: Key Parameters for the Development of Long-Acting Delivery Ocular Strategies. Mol Pharm [Internet]. American Chemical Society; 2015 Dec 10; Available from: http://dx.doi.org/10.1021/acs.molpharmaceut.5b00731

37. Gebbers N, Hirt-Burri N, Scaletta C, Hoffmann G, Applegate L. Water-filtered infrared-A radiation (wIRA) is not implicated in cellular degeneration of human skin. Ger Med Sci. 2007;5(Doc08).

38. Salcedo-Villanueva G, Kon-Jara V, Harasawa M, Cervantes-Coste G, Ochoa-Contreras D, Morales-Cantón V, et al. Vitreous humor thermodynamics during phacoemulsification. Int Ophthalmol [Internet]. 2014;35(4):557-64. Available from: http://dx.doi.org/10.1007/s10792- 
014-9983-z

39. Gokul KC, Gurung DB, Adhikary PR. Thermal effects of eyelid in human eye temperature model. Appl Math Informatics. 2014;32(5-6):649-63.

40. Goldmann H. Genesis of heat cataract. Arch Ophthalmol. 1933;9(314):0003-9950.

41. Verhoeff FH, Bell L, Walker CB. The pathological effects of radiant energy upon the eye. Proc Am Acad Art Sci. 1915;51(629):0065-6836.

42. Wolbarsht ML. Cataract from infrared lasers: evidence for photochemical mechanisms. Laser Light Ophthalmol. 1991;4:91-6.

43. Yu Z, Schulmeister K, Talebizadeh N, Kronschläger M, Söderberg P. Temperature-controlled in vivo ocular exposure to $1090-\mathrm{nm}$ radiation suggests that near-infrared radiation cataract is thermally induced. J Biomed Opt [Internet]. 2015;20(1):15003. Available from: http://dx.doi.org/10.1117/1.JBO.20.1.015003

44. Kolb H. Simple Anatomy of the Retina. In: Kolb H, Fernandez E, Nelson R, editor. Webvision: The Organization of the Retina and Visual System (Internet). Salt Lake Ciity (UT): University of Utah Health Sciences Center; 1995.

45. Iwami H, Pruessner J, Shiraki K, Brinkmann R, Miura Y. Protective effect of a laser-induced sub-lethal temperature rise on RPE cells from oxidative stress. Exp Eye Res. 2014;124:37-47.

46. Lin P, Quamo S, Ho K, Gladding J. Hyperthermia enhances the Cytotoxic Effects of Reactive Oxygen Species to Chinese Hamster Cells and Bovine Endothelial Cells in Vitro. Radiat Res. $1991 ; 126(1): 43-51$.

47. Knels L, Vatink M, Piazena H, De la Vega M, Gommel K, Lupp A, Roehlecke C, Mehner M, Funk RH. Effects of Narrow-band IR-A and Water-Filtered Infrared A on Fibroblasts. Photochem Photobiol. 2016;92(3):475-87.

48. Maroni P, Bendinelli P, Tiberio L, Rovetta F, Piccoletti R, Schiaffonati L. In vivo heat-shock response in the brain: signalling pathway and transcription factor activation. Mol Brain Res [Internet]. 2003 Nov 6;119(1):90-9. Available from: http://www.sciencedirect.com/science/article/pii/S0169328X03003802 
A) wIRA, $40 \mathrm{hpi}$, MOI 1

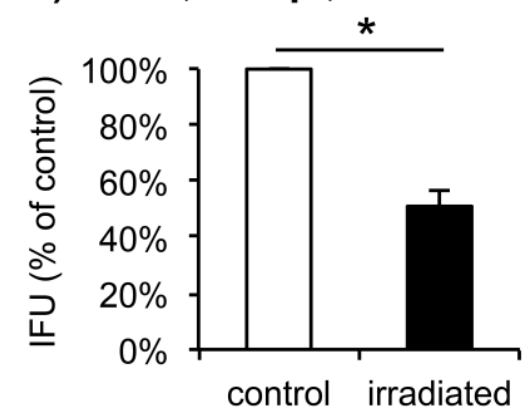

B) WIRA, EBs, MOI 1

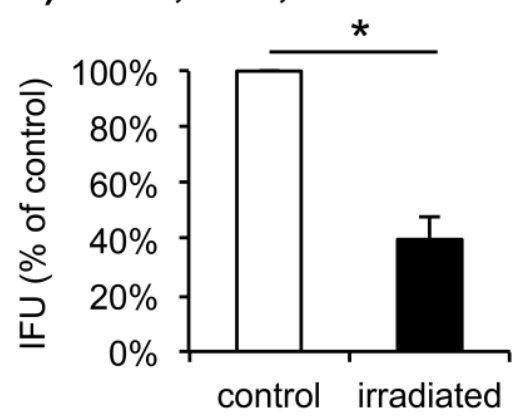

772

773

Figure S1.

774 The effect of wIRA alone (RG 780, $\left.2000 \mathrm{~W} / \mathrm{m}^{2}\right)$ on (A) C. trachomatis serotype B-infected cultures at 40 hours post infection and (B) EBs at MOI 1. 